\title{
REVIEW
}

\section{Recent advances in ultrafast semiconductor disk lasers}

\author{
Bauke W Tilma ${ }^{1}$, Mario Mangold ${ }^{1}$, Christian A Zaugg ${ }^{1}$, Sandro M Link ${ }^{1}$, Dominik Waldburger ${ }^{1}$, \\ Alexander Klenner ${ }^{1}$, Aline S Mayer ${ }^{1}$, Emilio Gini ${ }^{2}$, Matthias Golling ${ }^{1}$ and Ursula Keller ${ }^{1}$
}

The performance of ultrafast semiconductor disk lasers has rapidly advanced in recent decades. The strong interest from industry for inexpensive, compact, and reliable ultrafast laser sources in the picosecond and femtosecond domains has driven this technology toward commercial products. Frequency metrology and biomedical applications would benefit from sub-200-femtosecond pulse durations with peak powers in the kilowatt range. The aim of this review is to briefly describe the market potential and give an overview of the current status of mode-locked semiconductor disk lasers. Particular focus is placed on the ongoing efforts to achieve shorter pulses with higher peak powers.

Light: Science \& Applications (2015) 4, e310; doi:10.1038/lsa.2015.83; published online 17 July 2015

Keywords: lasers; modelocked lasers; semiconductor lasers; ultrafast lasers; vertical emitting lasers

\section{INTRODUCTION}

In recent decades, ultrafast lasers have evolved very rapidly toward ever-higher performance. Ultrafast lasers have three key characteristics that enable their application to market areas: First, their short pulse duration allows for high-resolution measurements in the timedomain. In other words, they are a near perfect ultrafast "flash" to measure high-speed phenomena. Second, because the laser energy is concentrated in the short pulse, they have very high peak powers, which enables key material interactions, the most important being "cold ablation" where the short optical pulse can remove or ablate almost any material without generating significant residual heat in the sample being processed. This technique allows for very precise micromachining of many existing and new types of materials and thin films in use today. It also has potential for use in future products. Additionally, it allows for new types of biomedical and tissue surgery applications. Third, the short temporal pulses have correspondingly large optical bandwidths, and this feature can be exploited for precise measurement diagnostics and metrology. A more detailed overview of these features and numerous other applications is given in several review articles ${ }^{1,2}$ and is beyond the scope of this study. The simplicity of semiconductor saturable absorber mirror (SESAM) mode-locked lasers combined with diode-pumped solid-state lasers (DPSSLs), which were developed during the $1990 \mathrm{~s}^{3,4}$ has resulted in many new, practical, and commercially available ultrafast laser systems. These laser systems are being used extensively in many relevant applications, where expensive, power-hungry, maintenance-intensive lasers are being replaced. The recent development of inexpensive, more compact semiconductor disk lasers (SDL) may open new markets, such as compact measurement equipment. This result will ultimately enable ultrafast lasers to access high-volume consumer markets, e.g., light detection and ranging (LIDAR) techniques in the automotive indus- try ${ }^{5}$ or natural user interface (NUI) applications in security and interactive media ${ }^{6}$.

For optical frequency comb applications, moving into the gigahertz pulse repetition rate regime has the advantage that the individual lines in the mode-locked frequency comb spectrum are spaced further apart, which increases the accessibility of the individual comb lines. Additionally, the power per comb line for a given average power is increased, which increases the signal-to-noise ratio in frequency comb metrology applications. The current field of gigahertz lasers is still dominated by the Kerr-lens mode-locked (KLM) Ti:sapphire laser, generating short femtosecond pulses with up to $10 \mathrm{GHz}$ repetition rates $^{7}$. Some recent developments in SESAM mode-locked DPSSLs ${ }^{8,9}$ may allow further increases in repetition rate beyond the limits of the Ti:sapphire laser. In addition, they can be pumped with relatively inexpensive high-power pump diode arrays and do not have to operate as close to the cavity stability edge as KLM Ti:sapphire lasers.

Ultrafast semiconductor lasers have the potential to be cheaper and more compact in comparison to ultrafast DPSSLs. This type of laser operates extremely well in the gigahertz pulse repetition rate regime, has the advantage of being mass producible on the wafer scale and can be monolithically integrated into more complex optical circuits ${ }^{10,11}$. Furthermore, the emission wavelength can be designed via bandgap engineering, and the repetition rate can easily be increased up to several tens of $\mathrm{GHz}$ without Q-switching instabilities.

The field of semiconductor mode-locked lasers can be divided into edge emitters and top emitters. Each of these technologies has its strengths and weaknesses.

Edge-emitting mode-locked lasers are predominantly two-section waveguide lasers. One section acts as an amplifier with an injected current through the forward biased $\mathrm{p}-\mathrm{i}-\mathrm{n}$ diode. The second section is kept in reverse bias to act as a fast saturable absorber. Most of these 
lasers are designed as a straight Fabry-Perot cavity ${ }^{10}$ or in a ring laser configuration $^{12,13}$. The advantage of edge-emitting mode-locked lasers is their compactness with repetition rates often well above $10 \mathrm{GHz}$. The planar integration method enables the direct integration of these lasers into more complex optical circuits, which makes them very attractive for telecommunication applications ${ }^{14,15}$. In terms of pulse duration, values down to $312 \mathrm{fs}$ for a $92-\mathrm{GHz}$ quantum dot (QD) laser at $1550 \mathrm{~nm}$ with $13.2 \mathrm{~mW}$ of output power ${ }^{16}$ have been reported. Most of these lasers however work in the picosecond pulse duration regime with maximum average output power levels of approximately $200 \mathrm{~mW}^{17}$. To reach a higher average power up to $800 \mathrm{~mW}$ and a peak power up to $6.5 \mathrm{~kW}$, an external semiconductor amplifier $^{18}$ or an external cavity ${ }^{19}$ and pulse compression were required, thus increasing the complexity of the system. In addition to the limited laser oscillator output power, edge emitters also have the disadvantage of a long gain interaction length, which increases the noise level ${ }^{20}$ and limits their suitability for frequency metrology and optical communication.

Top emitters, also known as SDLs or vertical external-cavity surface-emitting lasers (VECSELs) ${ }^{21}$, combine the advantages of a semiconductor gain material with the benefits of conventional DPSSLs. They also benefit from the wavelength flexibility and mass producibility imparted by semiconductor technology. In mode-locked operation, they share power scaling with SESAM mode-locked diodepumped thin disk lasers ${ }^{22}$, where the mode size can be increased, and the short gain interaction length leads to low noise operation. SDLs have the additional advantage that the SESAM can be integrated into the gain structure to increase the integration level, which is referred to as the mode-locked-integrated external cavity surface emitting laser (MIXSEL) ${ }^{23,24}$. Since the first demonstration of an SESAM mode-locked VECSEL in $2000^{25}$, the maximum average output power has been increased to $6.4 \mathrm{~W}^{26}$, the peak power increased to $4.35 \mathrm{~kW}^{27}$ and the pulse durations decreased to $107 \mathrm{fs}$ (fundamentally modelocked $)^{28}$ or even 60 fs in burst operation ${ }^{29}$. In Figure 1, a timeline is given, including important milestones of the mode-locked SDL technology, such as first demonstrations (blue) and current record achievements (red). In Table 1, an overview of these important achievements is given as well as some publications, which were of major importance at the time of publication. For comparison, we also included some record achievements from SESAM mode-locked electrically pumped VECSELs and mode-locked edge emitters. The recorded average output powers versus pulse lengths are given in Figure 2.

One of the advantages of SDLs is their wavelength flexibility. In continuous wave $(\mathrm{cw})$ operation, SDLs were operated at emission wavelengths ranging from $391 \mathrm{~nm}^{53}$ to $5.3 \mu \mathrm{m}^{54-56}$. The spectral coverage of cw SDLs has already been reviewed by several authors ${ }^{57-60}$. Using fourth harmonic generation, even wavelengths down to $244 \mathrm{~nm}$

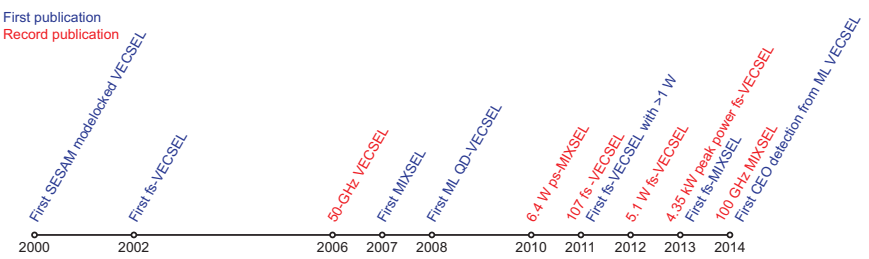

Figure 1 Timeline, including important milestones of fundamentally modelocked semiconductor disk lasers. First reported results (blue) and record reported results (red) are given. A complete list of publications, including references, is given in Table 1. were presented $^{61}$. To date, mode-locked SDLs cover a range of center wavelengths between $665 \mathrm{~nm}$ and $2 \mu \mathrm{m}$. An overview of important results achieved with fundamentally mode-locked SDLs in different wavelength regions is given in Figure 3 and Table 2. Most of the results were published in the 950-1040 nm wavelength region using InGaAs quantum wells (QWs). The excellent results in this wavelength range were enabled by the relatively straightforward fabrication of thin high reflective aluminium arsenide/gallium arsenide (AlAs/GaAs) distributed Bragg reflectors (DBRs) on GaAs substrates. Due to the large refractive index contrast between the two materials and their wellmatched lattice constants, high quality DBRs can be obtained. Furthermore, the low thermal impedance of the AlAs/GaAs system supports efficient heat removal.

In this study, we placed our focus on the recent developments of ultrafast optically pumped SDLs. These lasers support mode-locked average output powers at the multi-Watt level with low-noise femtosecond or picosecond pulse trains. The high-Q cavity and short interaction length with the semiconductor gain medium minimizes the noise level. The flexible external cavity enables straightforward repetition rate tuning.

This article is organized into three sections. In the following section, we will briefly repeat the principles of the SDL technology. The current technological possibilities, such as repetition rate flexibility and frequency comb stabilization, will be discussed in the second section. In the last section, we present a roadmap toward even shorter modelocked laser pulses with increased peak powers in the $\mathrm{kW}$ range.

\section{DEVICE PRINCIPLE}

\section{Vertical external-cavity surface-emitting laser (VECSEL)}

The VECSEL gain chip consists of a monolithically integrated highly reflective semiconductor DBR, a gain region containing several QW or QD layers and an antireflection section. The active region is optically pumped with an external low-brightness pump or electrically with a $\mathrm{p}$ $\mathrm{i}-\mathrm{n}$ configuration. The laser cavity is formed by the gain chip and an external output coupler (OC). A schematic of the VECSEL layer stack and a cw laser cavity is given in Figure $4 \mathrm{a}$ and $4 \mathrm{~b}$, respectively. With the help of the external OC, the laser can emit a circular beam of high quality, typically a diffraction-limited Gaussian beam $\left(\mathrm{TEM}_{00}\right)$. The combination of a thin-film gain medium and an external cavity enables simple power scaling by increasing the cavity mode and pump spot sizes on the gain chip while keeping the intensities constant ${ }^{32}$. To accomplish this goal, the radius of curvature (ROC) of the OC and the cavity length needs to match a given pump area. The mode-size power scalability in the semiconductor disk can be attributed mainly to the one-dimensional heat flow within the very thin semiconductor layer toward the heat sink underneath, which has a very high thermal conductivity $^{32,74,75}$. Since the first demonstration of the VECSEL in $1997^{21}$, cw output powers for optically pumped devices have been increased up to approximately $20 \mathrm{~W}$ in fundamental $\mathrm{TEM}_{00}$-mode and single frequency operation ${ }^{76,77}$ and $106 \mathrm{~W}$ in multi-mode opera$\operatorname{tion}^{78}$. For cw operation, the optically pumped VECSEL can be an efficient mode converter from low brightness diode laser arrays to a fundamental Gaussian beam with an optical-to-optical efficiency of more than $40 \%{ }^{77}$. Electrically pumped devices were demonstrated with $\mathrm{cw}$ output powers up to $500 \mathrm{~mW}^{79}$ in $\mathrm{TEM}_{00}$-mode and were recently pushed to $9 \mathrm{~W}$ in highly multi-mode operation ${ }^{80}$. The limited output power from electrically pumped VECSELs compared to that from the optically pumped devices is mainly due to a limitation in the power scaling principle and the increased optical losses from free carrier absorption in the doped layers of the VECSEL chip ${ }^{81,82}$. 
Table 1 Overview of fundamentally mode-locked semiconductor disk lasers. A selection is made based on the first reported result (blue), record reported result (red), and other important publications at the time of publication (black). For comparison, record reported values of electrically pumped SESAM mode-locked VECSELs and mode-locked edge emitters are given.

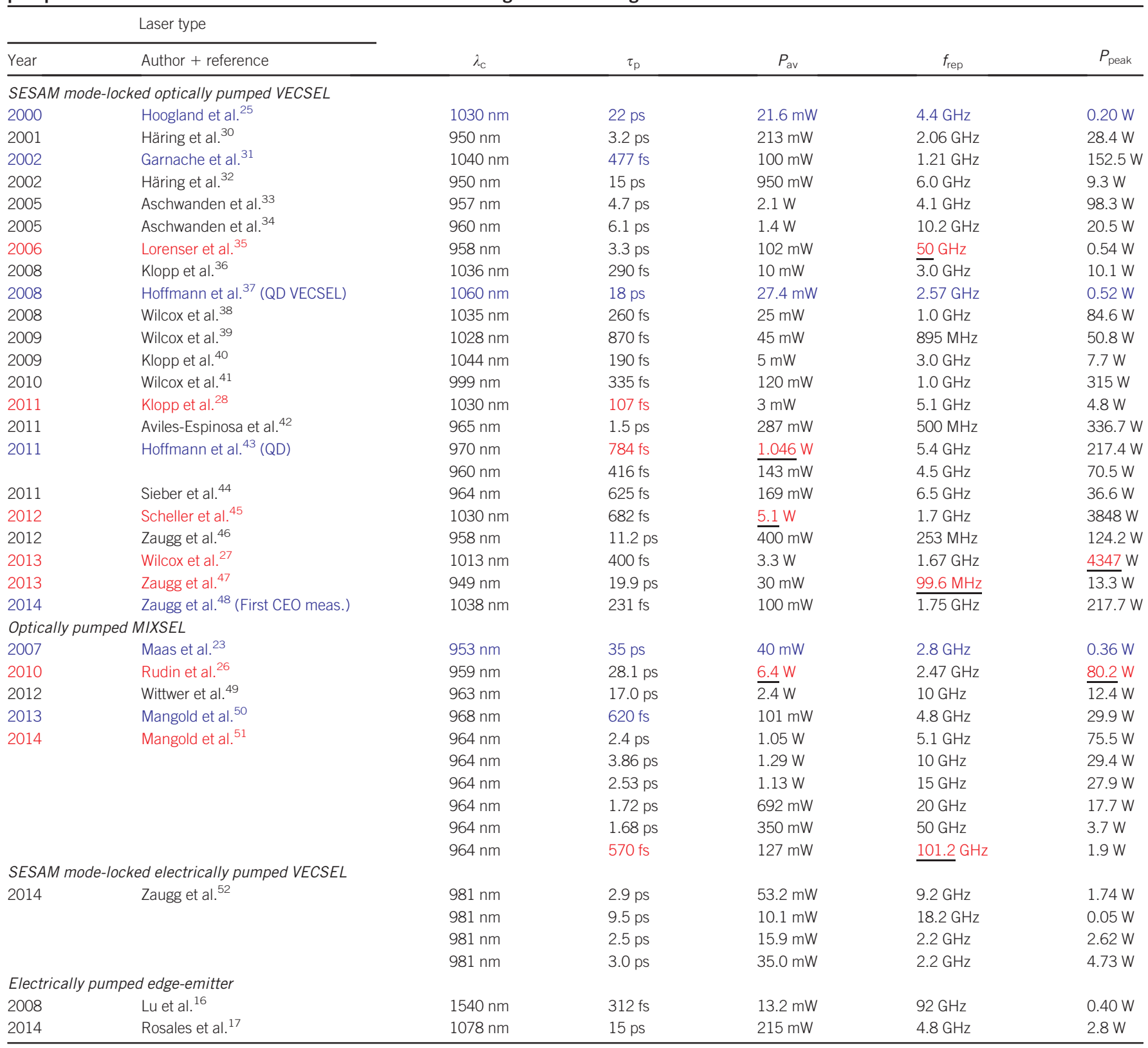

Semiconductor saturable absorber mirror (SESAM)

Passive modelocking with an SESAM ${ }^{3,83}$ is the state-of-the-art modelocking technique for VECSELs and was first demonstrated in $2000^{25}$. The first review of SESAM mode-locked VECSELs was given in $2006^{58}$. In the simplest configuration, an SESAM-mode-locked VECSEL is realized in a V-shaped cavity as shown in Figure 5b. In Figure 5a, a schematic of an SESAM layer stack is given. The SESAM consists of a highly reflective semiconductor DBR, one or more QW or QD layers, and some top layers to control the absorption behavior and dispersion $^{84}$. The QW or QD layer(s) act as a saturable absorber. A typical nonlinear reflectivity curve, experimentally accessible with the technique described by Maas et al. ${ }^{85}$, is shown in Figure 6a. The reflectivity of the SESAM at very low probe pulse fluences $\left(F_{\mathrm{p}}=E_{\mathrm{p}} / A\right.$, where $F_{\mathrm{p}}$ is the pulse fluence, $E_{\mathrm{p}}$ the pulse energy and $A$ the cavity mode area) is defined as $R_{\text {lin. }}$ The absorbed part consists of nonsaturable losses $\Delta R_{\mathrm{ns}}$ and a saturated part $\Delta R$, also referred to as the modulation depth. The saturation fluence $F_{\text {sat }}$ is defined as the fluence at, which the reflectivity is increased by $\Delta R / e . F_{\text {sat }}$ is strongly dependent on the design and intrinsic properties of the SESAM and can be optimized for different lasers. For mode-locked VECSELs the saturation fluence of the SESAM should be kept low to start and stabilize passive modelocking $^{86}$. At pulse fluences far above the saturation fluence, inverse saturable absorption effects, represented by $F_{2}$, are observed ${ }^{87}$; the most prominent of these effects is two-photon absorption. $F_{2}$ leads to a reduction in reflectivity proportional to $\exp \left(-F_{\mathrm{p}} / F_{2}\right)$, which is referred to as the rollover of the SESAM.

The mode-locked VECSELs benefit from a fast self-amplitude modulation of the SESAM. This can be obtained by band filling 


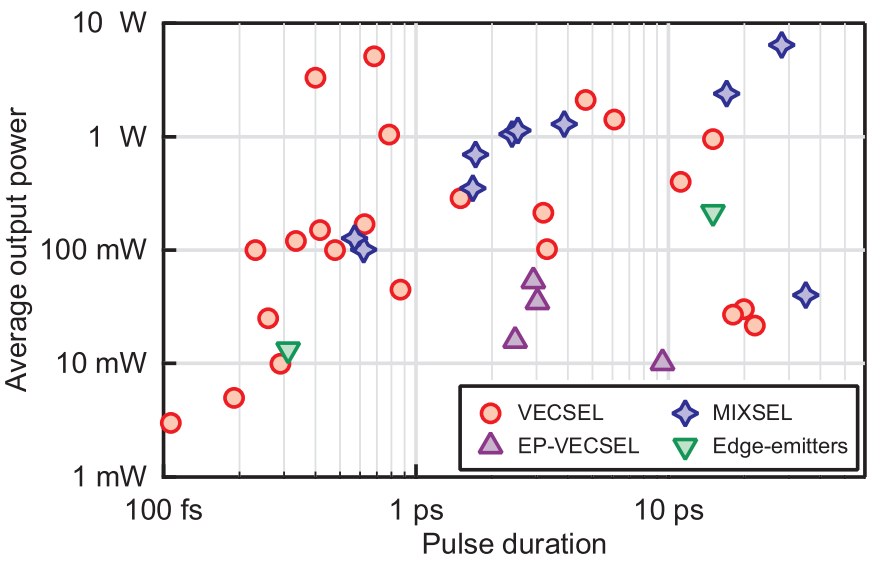

Figure 2 Selected overview of achieved average output power of fundamentally mode-locked optically pumped semiconductor lasers versus pulse duration according to Table 1. For comparison, record-reported values of electrically pumped SESAM mode-locked VECSELs and mode-locked edge-emitters are added.

(i.e., absorption is reduced by the Pauli exclusion principle by filling up the available states in the conduction band) followed by a fast recovery of the saturated absorption. There are many different ways to obtain a fast recovery for semiconductor materials, such as a controlled number of mid-gap traps introduced by either low-temperature epitaxial growth of the absorber layer ${ }^{88,89}$, selective doping ${ }^{90}$, inherent material defects $^{91}$, implantation induced defects through ion-bombardment ${ }^{92,93}$, or interface or surface defects ${ }^{94}$. Alternatively, exciton nonlinearities can be used with the nonlinear Stark effect ${ }^{38,95-97}$. These different SESAM nonlinearities have been reviewed in more detail by Keller and Tropper in $2006^{58}$. The related SESAM damage threshold has been studied by Saraceno et al. ${ }^{98}$ in 2011 . The absorber reaches transparency above certain pulse fluence as long as non-saturable losses can be minimized.

The dynamic reflectivity change of the SESAM in combination with the dynamic saturation of the semiconductor gain governs the pulse formation mechanism of mode-locked VECSELs. These dynamics are schematically represented in Figure 7. The incoming pulse (black) reduces the losses in the absorber (red) at lower energies than the gain saturation occurs (green). Therefore, a net gain window opens up in which the pulse can be amplified. In addition to the saturation fluence and modulation depth of the SESAM, these recovery dynamics play a crucial role in the pulse formation process ${ }^{86,99}$. The induced Starkshift was reported to exhibit very fast recovery dynamics on the order of a few hundred femtoseconds ${ }^{38}$. The recovery dynamics of bandfilled saturable absorbers depends on intraband, interband and trap relaxation processes and typically involve a combination of recovery steps $^{88}$, which can be modeled with a bitemporal response function via a simplified approach. In Figure 6b, a typical pump-probe measurement ${ }^{100}$ of the recovery time of an SESAM is depicted. The fast recovery component with an exponential decay time $\tau_{\text {fast }}$ and amplitude $A_{\text {fast }}$ is induced by the intraband thermalization process and has a recovery time constant of a few hundred fs. The slow recovery component with an exponential decay time $\tau_{\text {slow }}$ and an amplitude $1-A_{\text {fast }}$ is induced by interband recombination processes, mid-gap trap capture processes or interface/surface recombination processes. The combination of the fast and slow components and their relative amplitudes determine the total bitemporal recovery time of the SESAM. A fast recovery of the SESAM is one of the crucial parameters for achieving

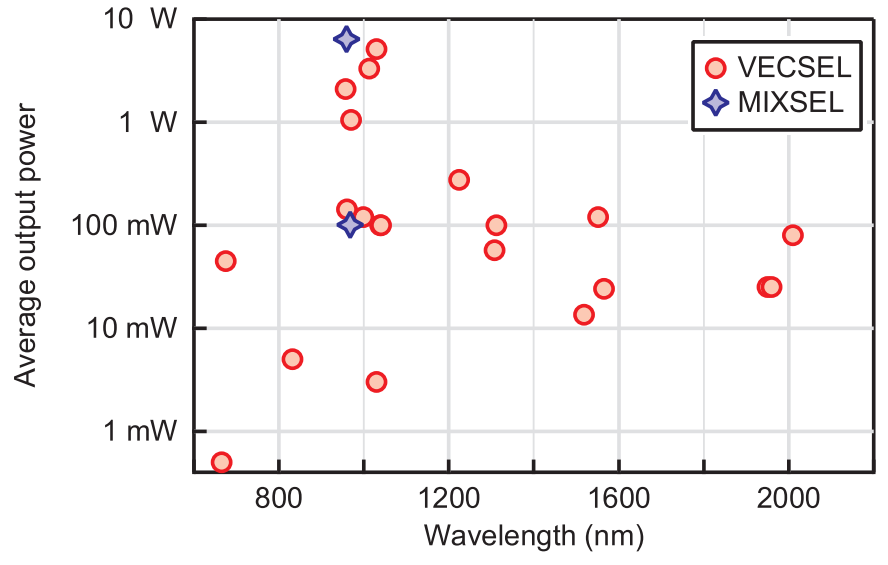

Figure 3 Overview of achieved average output powers of fundamentally modelocked semiconductor disk lasers at different wavelengths (a selection is made based on first or best published results). A list of shown values, including references is given in Table 2.

sub-picosecond pulse durations from SESAM mode-locked VECSELs ${ }^{43,50}$.

Other VECSEL modelocking mechanisms: graphene saturable absorber and self-modelocking

In addition to the standard SESAM modelocking techniques, several other VECSEL modelocking techniques have been published. In 2013, Zaugg et al. ${ }^{101}$ presented a VECSEL mode-locked with a single layer graphene saturable absorber mirror (GSAM). Despite the encouraging start with the demonstration of a very broad tunable operation bandwidth of $46 \mathrm{~nm}$ and a very fast absorber recovery time, the novel GSAMs have not advanced beyond the proof-of-principle status so far. Currently, the GSAM mode-locked VECSELs suffer from a limited average power in the milliwatt regime, which is caused by excessive nonsaturable losses and the low damage threshold. Higher output power levels of up to $10 \mathrm{~W}^{102}$ from GSAM-mode-locked VECSELs were claimed recently; however, evidence for clean modelocking has not been provided to date.

Another modelocking mechanism reported recently is the so-called self-mode-locked VECSEL or the KLM-VECSEL ${ }^{103-106}$. No apparent saturable absorber is used in these laser cavities, and a hard aperture is inserted in front of the OC or highly reflective end mirror. In analogy to solid-state lasers, the modelocking mechanism was initially explained by the Kerr lensing effect in the gain region, and the effect can be enhanced with an extra Kerr medium inside the cavity ${ }^{107}$. The reported results were promising, and a more detailed set of measurements ${ }^{108}$ was presented only recently ${ }^{109}$. However, it remains to be observed whether these lasers are really fully mode-locked. We have observed in our labs that more sophisticated diagnostics are required for ultrafast SDLs to confirm stable modelocking. Furthermore, the physical origin of the nonlinear effects in the gain medium and more detailed noise characterization will require more research efforts.

\section{Mode-locked integrated external-cavity surface-emitting laser (MIXSEL)}

A logical following step toward more compact high-power semiconductor mode-locked lasers is the MIXSEL. The MIXSEL combines the active part of a VECSEL with the saturable absorber of an SESAM in a single semiconductor chip. In this way, stable and self-starting 
Table 2 Overview of important results achieved with fundamentally mode-locked SDLs in different wavelength regions.

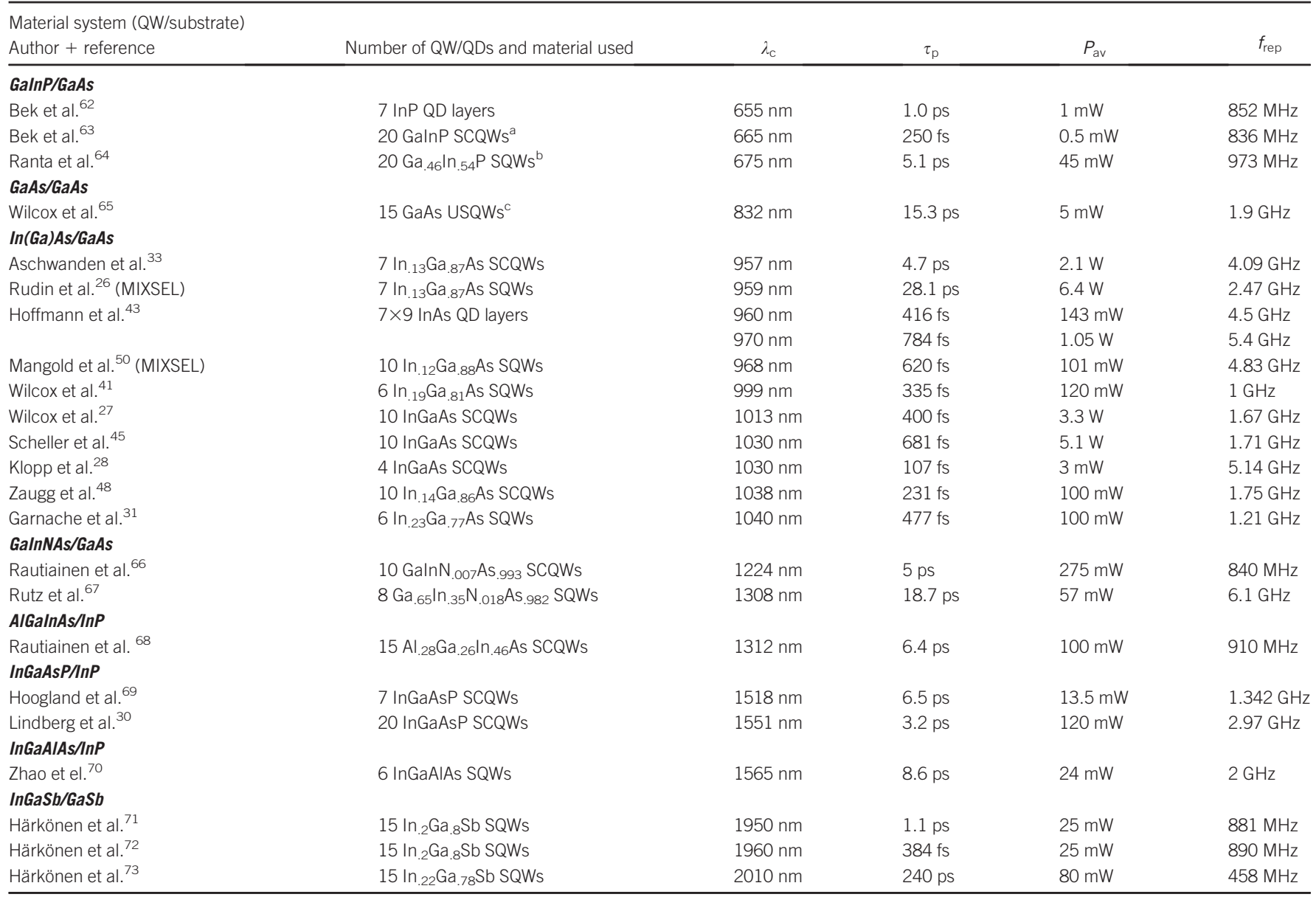

${ }^{\text {a } S C Q W s}=$ strain compensated quantum wells.

${ }^{\mathrm{b}} \mathrm{SQWS}=$ strained quantum wells.

${ }^{\mathrm{c}}$ USQW $=$ unstrained quantum wells.

modelocking can be achieved in a simple straight cavity. Maas et al. demonstrated for the first time a MIXSEL in $2007^{23}$. The simple straight cavity of the MIXSEL reduces the complexity of the laser and enables repetition rate scaling up to at least $100 \mathrm{GHz}^{51}$.

A schematic design of a MIXSEL layer stack is given in Figure 8. The MIXSEL layer stack includes two DBRs underneath the active area. The first mirror is designed to reflect residual pump light and be transparent to the laser light. This pump DBR inhibits pre-saturation of the absorber by residual pump light. The mirror underneath is designed to be highly reflective for the lasing wavelength. The saturable absorber is placed in between the two DBRs in an antinode of the standing wave.

The first MIXSELs had a resonant design in which the electric field enhancement at the absorber position was increased compared to the field in the gain section. This enhancement was implemented to reduce the saturation fluence of the absorber, and therefore, saturate the absorber at lower pulse energies than the gain ${ }^{110}$. However, the resonant design is very sensitive to growth errors, and the group delay dispersion (GDD) fluctuates very strongly $\left( \pm 10000 \mathrm{fs}^{2}\right)$ around the lasing wavelength. With the development of novel QD absorbers, the saturation fluence was decreased, whereas the modulation depth was kept in the desired range ${ }^{111}$. These QDs were used in the first antiresonant MIXSEL structure, with which a record high average output power of $6.4 \mathrm{~W}$ in 28 -ps pulses at $2.5-\mathrm{GHz}$ repetition rate was obtained $^{26}$. The trade-off of those QD absorbers is the relatively long slow recovery time, which sets a lower limit to the achievable pulse length. Newly developed QW-based saturable absorbers have overcome this issue. Low temperature grown QWs embedded in AlAs yield fast recovery dynamics and low saturation fluences despite the long annealing process during the subsequent epitaxy. These fast recovery dynamics and low saturation fluences are necessary for a very fast MIXSEL $^{112}$. This resulted in femtosecond pulses from a MIXSEL for the first time ${ }^{50}$, generating 620 -fs pulses with a $4.8-\mathrm{GHz}$ repetition rate and an average output power of $101 \mathrm{~mW}$. With the same MIXSEL chip, it was possible to stepwise increase the pulse repetition rate from $\approx 5 \mathrm{GHz}$ up to $100 \mathrm{GHz}^{51}$ by reducing the cavity length from $\approx 30 \mathrm{~mm}$ down to $1.5 \mathrm{~mm}$ and changing the OC to maintain stable cavity configurations. At the record high $100-\mathrm{GHz}$ pulse repetition rate, we obtained pulses with a duration of only $570 \mathrm{fs}$ and an average output power of $127 \mathrm{~mW}$.

\section{STATE-OF-THE-ART ULTRAFAST SEMICONDUCTOR DISK LASERS (SDLS)}

The performance of ultrafast SDLs rapidly improved over the last decade. Cw SDLs already have been successfully commercialized, for 
a VECSEL gain chip

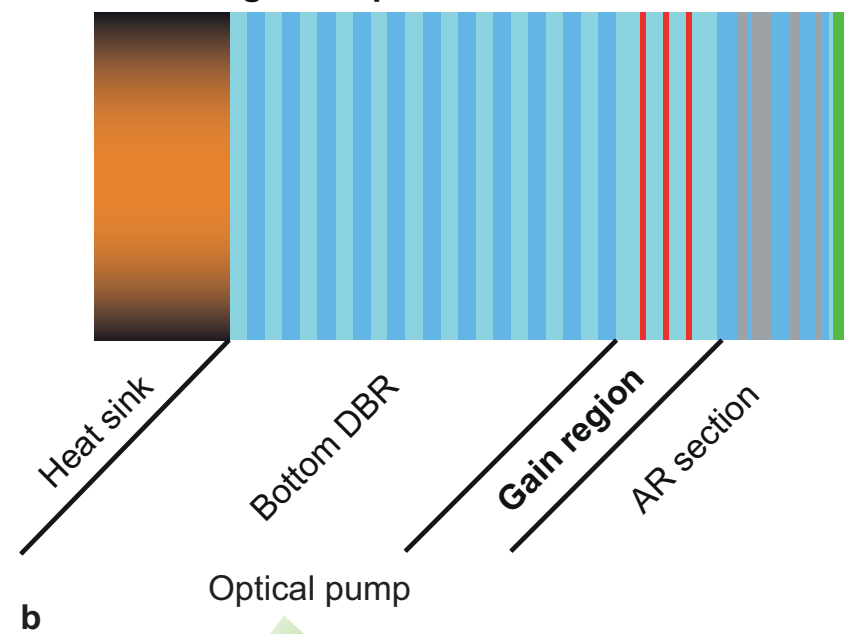

b

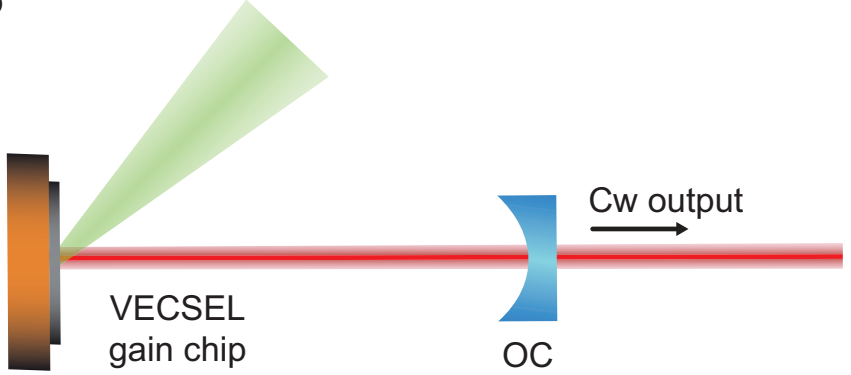

Figure 4 (a) Basic layer stack of a VECSEL containing a highly reflective bottom DBR, a gain region containing multiple quantum well (QW) or QD layers and an antireflection (AR) section. (b) Schematic diagram of a cw cavity containing a VECSEL gain chip and an OC. The VECSEL is optically pumped, in this case under an angle of $45^{\circ}$.

example, by Coherent $\AA$ to realize a $20-\mathrm{W}$ frequency doubled $532 \mathrm{~nm}$ $\mathrm{TEM}_{00}$ laser for pumping Ti:sapphire lasers ${ }^{113}$. The mode-locked SDL technology is able to operate over a large wavelength range with output power levels far exceeding the powers that can be achieved with modelocked edge emitters. In addition, the mode-locked SDL technology platform can be used over a large pulse repetition rate regime ranging from $100 \mathrm{MHz}$ up to $100 \mathrm{GHz}$. Furthermore, the low timing jitter and amplitude noise of SDLs is of significant benefit for applications, where the mode-locked frequency comb has to be stabilized. In this section, we will discuss the current possibilities in repetition-rate tuning and in frequency-comb stabilization.

\section{Pulse repetition-rate scaling and tuning}

Different applications require different repetition rates. For example, biomedical imaging in the multi-photon regime requires lower pulse repetition rates to reduce the average power while maintaining a high peak power, whereas high repetition rates are beneficial for telecommunication, data communication, LIDAR applications and optically sampled analog-to-digital converters (ADCs). Fundamentally mode-locked SDLs have been demonstrated at repetition rates starting from $100 \mathrm{MHz}^{46,47}$ up to $100 \mathrm{GHz}^{51}$. The highest performance with respect to peak power, average power, and pulse duration was achieved at repetition rates between 1 and $10 \mathrm{GHz}$ (Figure 9). In contrast to DPSSLs, SDLs do not suffer from Q-switching instabilities ${ }^{114}$ in the gigahertz regime.

Achieving low repetition rates to increase the peak power is very challenging for semiconductor mode-locked lasers because they a SESAM

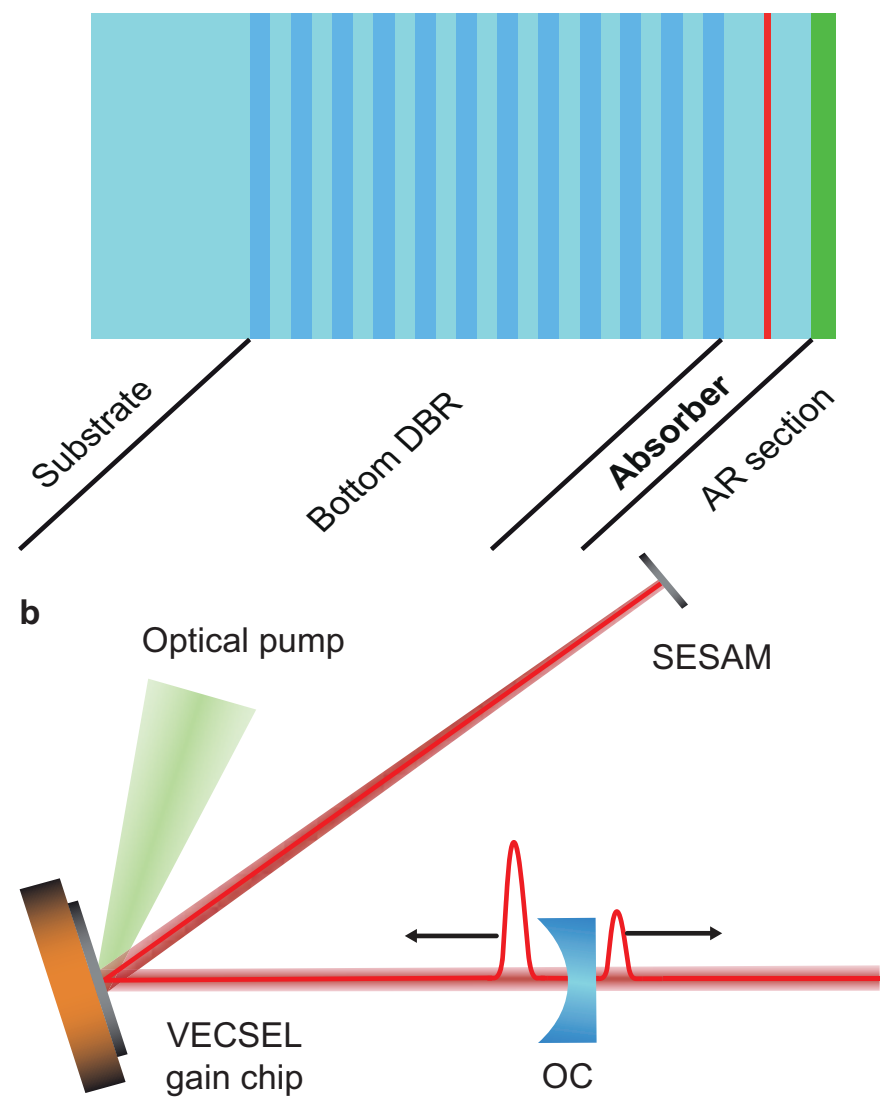

Figure 5 (a) Basic layer stack of an SESAM containing a highly reflective bottom DBR, an absorber region containing one or multiple QW or QD layers, and an antireflection section. (b) Schematic diagram of a V-shaped SESAM mode-locked VECSEL cavity containing a VECSEL as folding mirror, an SESAM and an output coupler (OC) as end mirrors. The VECSEL is optically pumped, in this case under an angel of $45^{\circ}$.

exhibit a carrier lifetime that is several orders of magnitude shorter than for typical ion-doped glass or crystalline gain materials, which denotes that the semiconductor gain material is able to store energy for only a limited time of a few nanoseconds. At lower repetition rates, where the separation between subsequent pulses is longer, splitting the energy into two or more pulses represents a gain advantage for the laser, which introduces modelocking instabilities, such as multipulsing or harmonic modelocking. This effect has been studied in more detail by Saarinen et al. ${ }^{115}$

In the high pulse repetition rate regime, scaling the repetition rates above $10 \mathrm{GHz}$ becomes more challenging due to the short external cavity length. Nevertheless, repetition rates up to $50 \mathrm{GHz}$ have been obtained with a fundamentally mode-locked VECSEL ${ }^{35}$. Recently, the maximum repetition rate has been increased up to $100 \mathrm{GHz}$ with the MIXSEL $^{51}$, which was possible due to the simple linear cavity. The cavity length was only $1.5 \mathrm{~mm}$ in this case. To further reduce the cavity length and increase the repetition rate, implementing an external OC to an attached flat ${ }^{116}$ or concave ${ }^{117}$ mirror could be an option. Although the highest average output power levels with the VECSEL and MIXSEL technology have been achieved in the 1-10 GHz range, the MIXSEL technology has demonstrated record performance in the 10-100 GHz range. Above $10 \mathrm{GHz}$, the MIXSEL has delivered the 

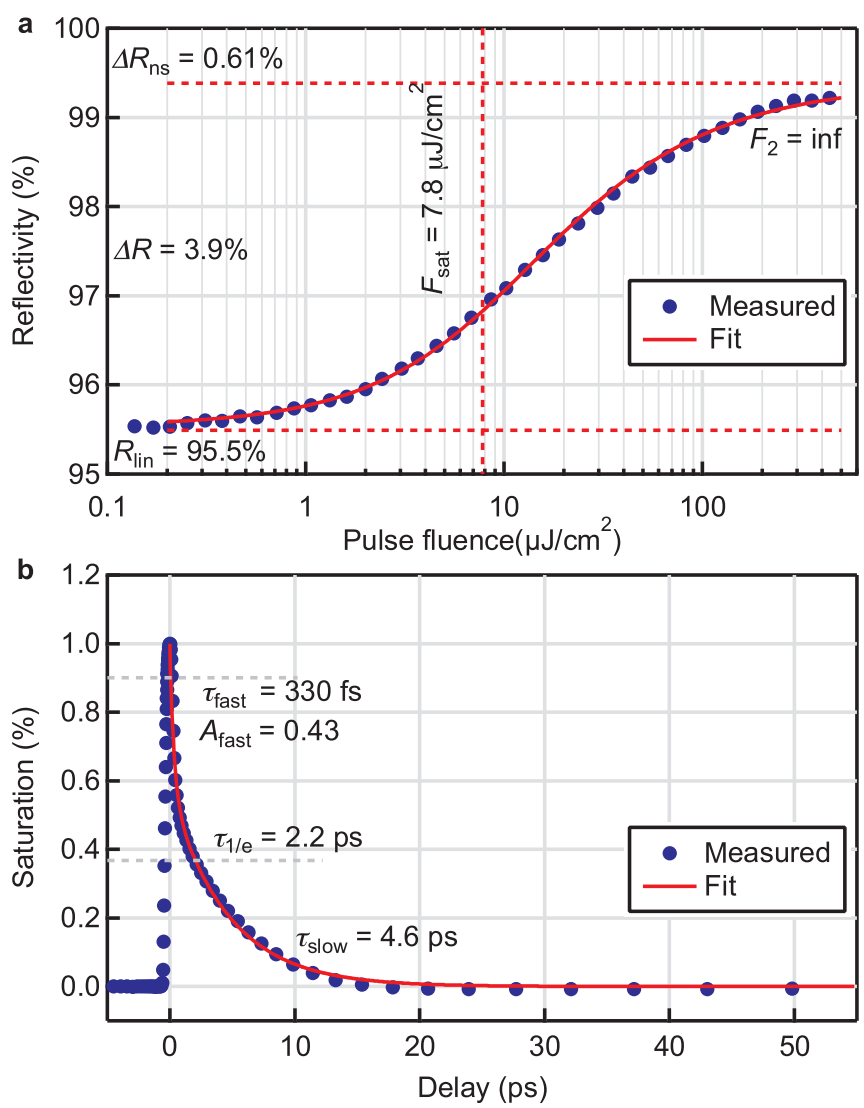

Figure 6 Saturation behavior of a typical SESAM: (a) Nonlinear reflectivity behavior as a function of the pulse fluence. (b) Time-resolved differential reflectivity (pump-probe) measurement, including a fit with a double exponential recovery dynamic for a bitemporal recovery model.

highest peak power of any mode-locked laser technology, as shown in Figure $10^{51}$.

The SDL technology supports very simple repetition rate tuning by changing the cavity length with the OC or the SESAM on a linear translation stage. A repetition rate-tuning range of several $\mathrm{GHz}$ has been demonstrated with an SESAM-mode-locked VECSEL in the $1-10 \mathrm{GHz}$ repetition rate range without changing any cavity

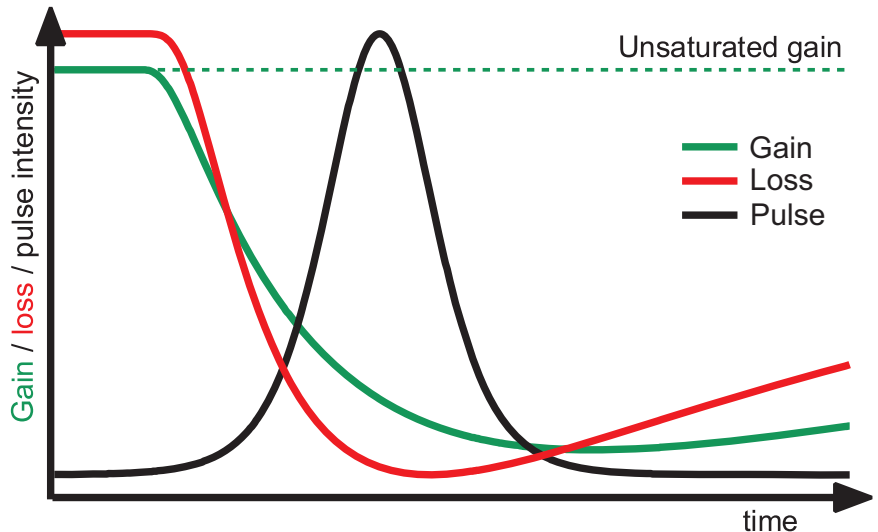

Figure 7 Schematic of the basic pulse formation process in an SESAM modelocked VECSEL. The optical pulse (black) saturates the loss in the SESAM (red) at lower pulse energies than the VECSEL gain chip (green). This leads to a short time window with a total positive net gain (i.e., a net gain window).

\section{a MIXSEL}
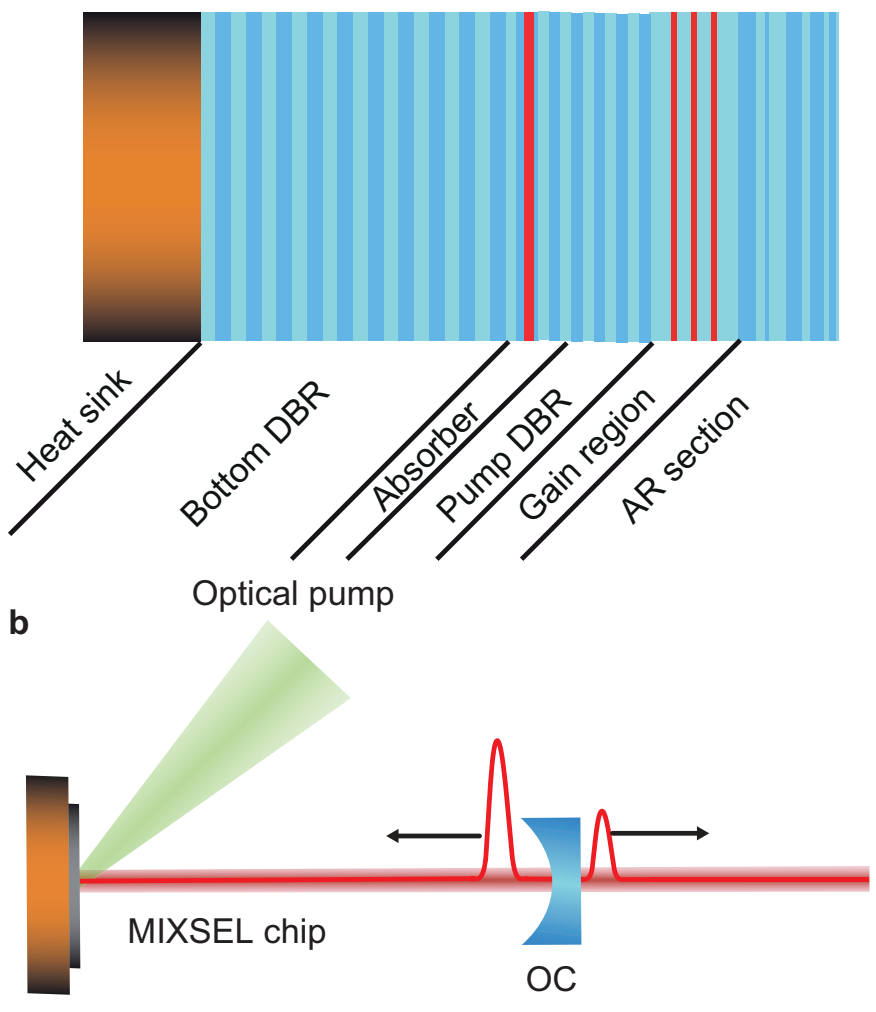

Figure 8 (a) Basic layer stack of a MIXSEL containing a highly reflective bottom DBR, a QW or QD absorber, a pump DBR, and a gain region containing multiple QW or QD layers and an antireflection section. (b) Schematic diagram of a MIXSEL cavity emitting short laser pulses. The MIXSEL is optically pumped under an angle of $45^{\circ}$.

components $^{86,118,119}$. With the MIXSEL, a scaling range from 5 to $100 \mathrm{GHz}$ has been achieved using the same MIXSEL semiconductor chip but different $\mathrm{OC}^{51}$. The transmission and ROC of the OC had to be adapted to ensure a stable cavity configuration. Smaller repetition rate changes could be achieved without changing the OC. This relatively

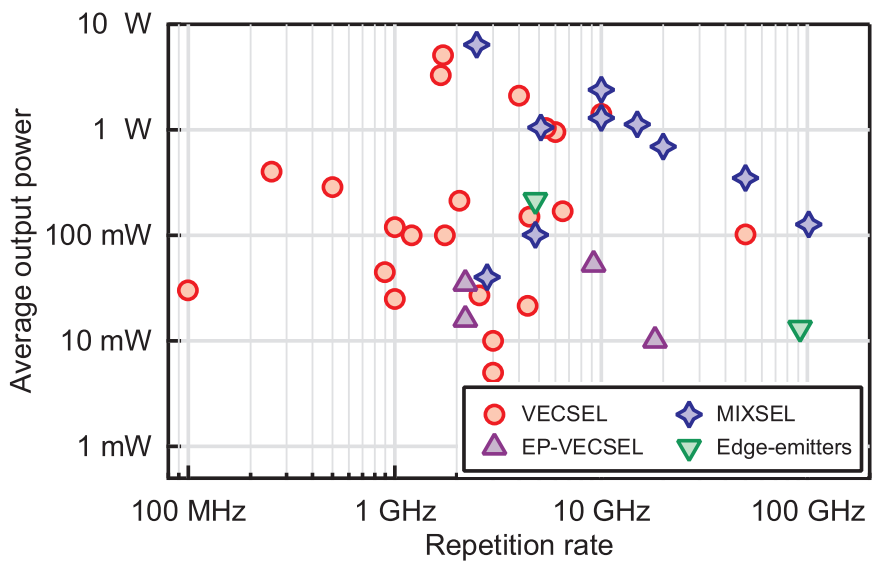

Figure 9 Selected overview of achieved average output powers of fundamentally mode-locked optically pumped semiconductor disk lasers versus pulse repetition rates according to Table 1 . For comparison, reported record values of electrically pumped SESAM mode-locked VECSELs and mode-locked edge emitters are included. 


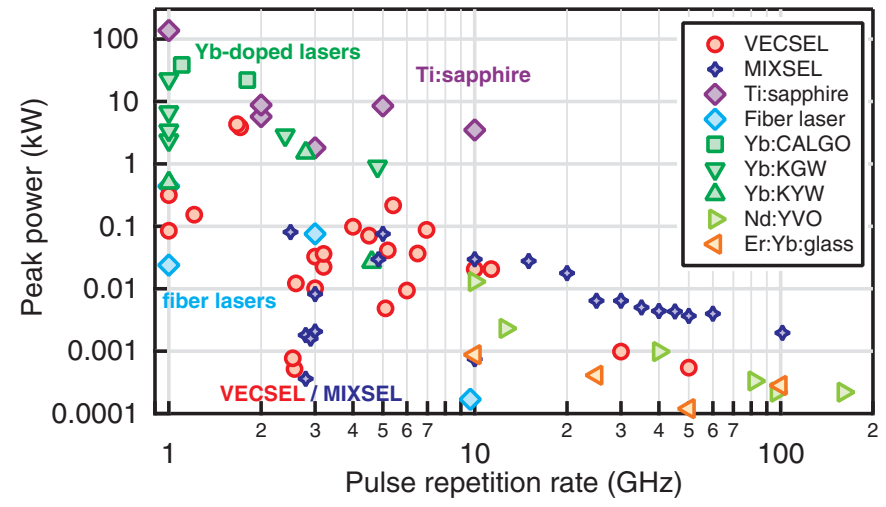

Figure 10 Peak power of fundamentally mode-locked lasers with gigahertz pulse repetition rates: The simple and inexpensive MIXSEL technology combines high power with short pulse durations to achieve record high average and peak powers and greater than $10-\mathrm{GHz}$ pulse repetition rates (Figures reprinted with permission from Mangold et al. ${ }^{51}$ ).

simple change in repetition rate is an advantage in case the repetition rate of the laser has to be stabilized to an external reference source.

\section{Frequency comb stabilization}

The low timing jitter and amplitude noise of mode-locked DPSSLs ${ }^{120}$ have enabled several records for frequency comb generation ${ }^{121}$ and data transmission rates ${ }^{122}$. Comparable low-noise performance has been achieved with SESAM-mode-locked VECSELs ${ }^{123-126}$ and MIXSELs ${ }^{127}$, both in free-running operation as well as when the repetition rate is stabilized to an external reference source. In Figure 11, the timing phase noise from a selection of published VECSELs ${ }^{125,126}$ and MIXSEL ${ }^{127}$ is shown both in free-running operation and stabilized to an external reference source. For comparison, the free-running timing phase noise of a GHz SESAM-mode-locked Yb:CALGO laser is added ${ }^{128}$. In Table 3, the integrated rms timing jitter and amplitude noise are given. In contrast to edge-emitting semiconductor lasers, SDLs have a very short interaction length of the optical pulse with the gain layers and the cavity losses are very low. The high-Q cavity intrinsically imposes a lower noise level ${ }^{129,130}$ than semiconductor edge emitters ${ }^{131-133}$.

The low-noise behavior and the possibility of stabilizing the repetition rate to an external reference source make ultrafast VECSELs and MIXSELs attractive laser sources for compact and cost-efficient frequency comb metrology applications. For those applications, the carrier envelope offset frequency $\left(f_{\mathrm{CEO}}\right)^{134}$ and pulse repetition rate have to be stabilized ${ }^{135,136}$. In the spectral domain, the pulse repetition frequency $f_{\text {rep }}$ defines the distance between the individual frequency

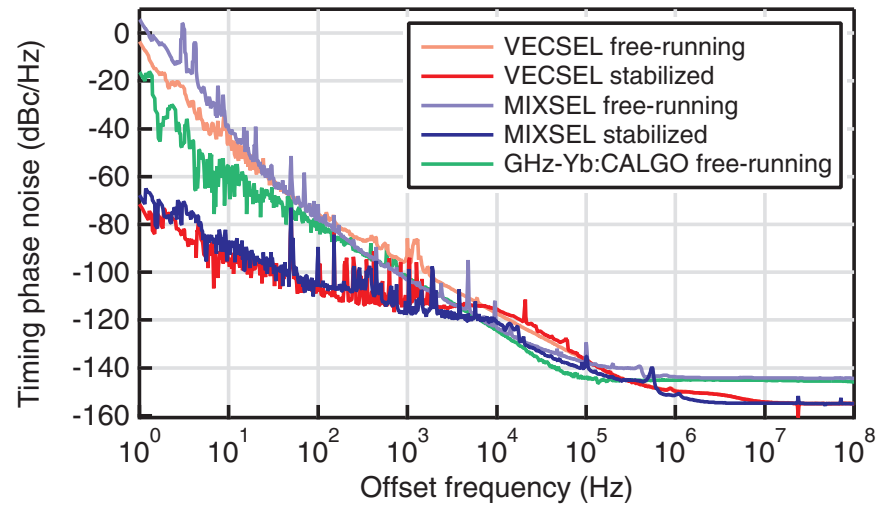

Figure 11 Single sideband timing phase noise power spectral density of freerunning (light) and actively stabilized (dark) VECSEL (red) ${ }^{125,126}$, MIXSEL (blue $^{127}$ and for comparison a free-running GHz Yb:CALGO (green) ${ }^{128}$ modelocked laser.

comb lines and $f_{\mathrm{CEO}}$, the offset to DC. The mode-locked frequency comb is then fully described by $f_{\mathrm{CEO}}+\mathrm{m} f_{\text {rep }}$, where $\mathrm{m}$ is an integer. With the stabilization of both frequencies, the complete comb can be locked, which has already been demonstrated for Ti:sapphire lasers ${ }^{137}$, fiber lasers ${ }^{138}$, thin disk lasers ${ }^{139}$, and DPSSLs ${ }^{121}$. The detection of the CEO-frequency $f_{\mathrm{CEO}}$ is very challenging for ultrafast SDLs. The most widespread method relies on the generation of a coherent octavespanning supercontinuum (SC), which is launched into an $f$-to- $2 f$ interferometer to detect the CEO beat notes ${ }^{134}$. The SC is typically generated in a highly nonlinear photonic crystal fiber (PCF $)^{140}$. Recent work on SDLs has increased the peak power up to the level necessary for SC generation. Nevertheless, an octave-spanning SC has not yet been achieved by directly launching the output of a mode-locked SDL into a $\mathrm{PCF}^{27}$. Additional passive compression to 150 -fs pulses with an average output power of $270 \mathrm{~mW}$ corresponding to a $1015-\mathrm{W}$ peak power (or 220 -fs pulses at $520 \mathrm{~mW}$ and $1333 \mathrm{~W}$ peak power) was not sufficient to generate the octave spanning $\mathrm{SC}^{141}$ due to the limited average output power from the laser. An obvious intermediate step is pulse amplification in an active fiber amplifier, which has already been demonstrated in the $1.57-\mu \mathrm{m}$ wavelength region ${ }^{142}$ to generate a wide spectrum for broadband WDM telecommunication technology ${ }^{143}$. In this experiment, 14.4-ps pulses with an average output power of $100 \mathrm{~mW}$ from the mode-locked VECSEL were amplified to $4.5 \mathrm{~W}$ average powers in 15.5-ps pulses. These pulses where launched into the highly nonlinear fiber to generate a broad (most likely incoherent) continuum from $1320 \mathrm{~nm}$ to $2000 \mathrm{~nm}$. Furthermore, this range does

Table 3 Integrated rms timing jitter and amplitude noise of the results depicted in Figure 11.

\begin{tabular}{|c|c|c|c|c|c|c|}
\hline Laser & Repetition rate $(\mathrm{GHz})$ & Output power (mW) & $f_{\text {low }}(\mathrm{Hz})$ & $f_{\text {high }}(\mathrm{MHz})$ & rms timing jitter (fs) & rms amplitude noise \\
\hline \multicolumn{7}{|l|}{ VECSEL } \\
\hline \multirow[t]{2}{*}{ Free-running $^{125}$} & 2 & 40 & 1 & 100 & 34740 & $0.45 \%(1 \mathrm{~Hz}, 40 \mathrm{MHz})$ \\
\hline & & & 100 & 100 & 201 & \\
\hline \multirow[t]{2}{*}{ Stabilized $^{126}$} & 2 & 40 & 1 & 100 & 58 & $0.40 \%(1 \mathrm{~Hz}, 40 \mathrm{MHz})$ \\
\hline & & & 100 & 100 & 47 & \\
\hline \multicolumn{7}{|l|}{ MIXSEL } \\
\hline \multirow[t]{2}{*}{ Free-running ${ }^{127}$} & 2 & 645 & 1 & 100 & 141721 & $0.11 \%(1 \mathrm{~Hz}, 40 \mathrm{MHz})$ \\
\hline & & & 100 & 100 & 145 & \\
\hline \multirow[t]{2}{*}{ Stabilized $^{127}$} & 2 & 701 & 1 & 100 & 69 & $0.15 \%(1 \mathrm{~Hz}, 40 \mathrm{MHz})$ \\
\hline & & & 100 & 100 & 32 & \\
\hline \multicolumn{7}{|l|}{$G H z-Y b: C A L G O$} \\
\hline Free-running ${ }^{128}$ & 1 & 1700 & 1 & 0.1 & 16000 & $0.05 \%(1 \mathrm{~Hz}, 1 \mathrm{MHz})$ \\
\hline
\end{tabular}



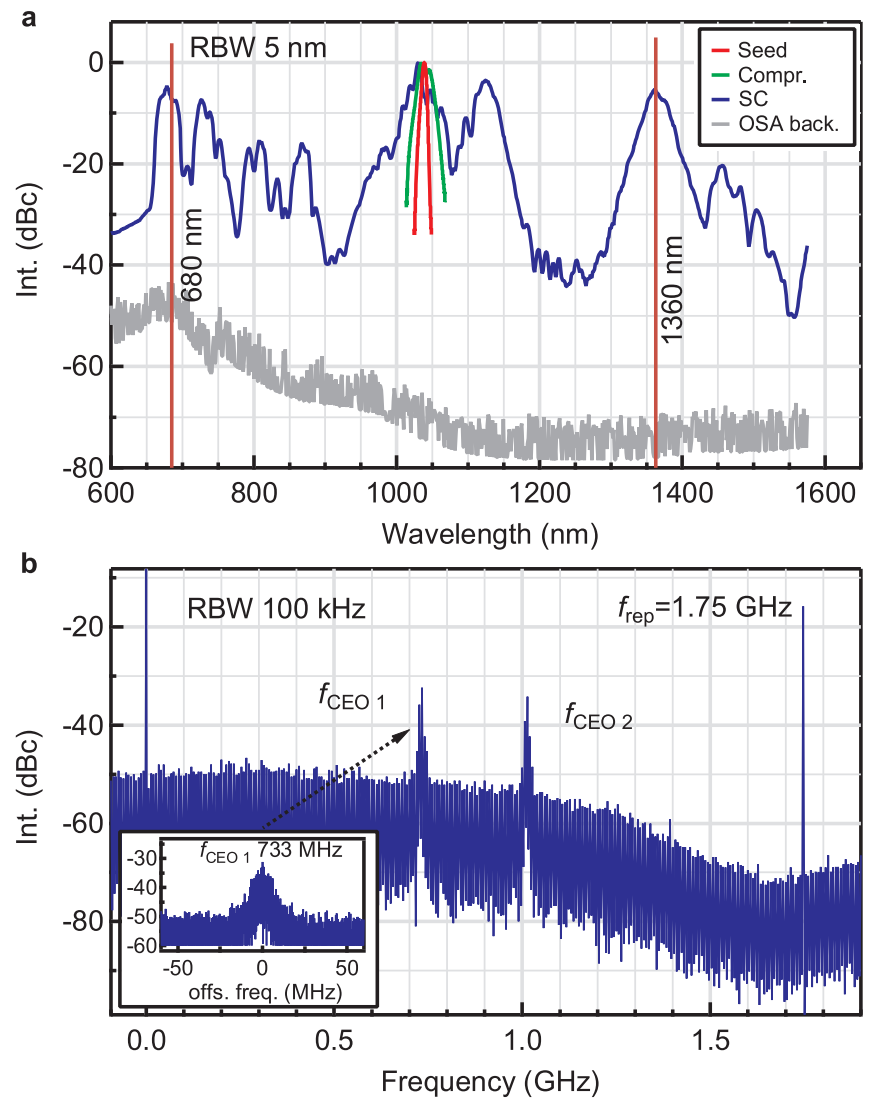

Figure 12 (a) Measured coherent octave-spanning supercontinuum (blue) generated in a highly nonlinear PCF. The $1360 \mathrm{~nm}$ and $680 \mathrm{~nm}$ spectral components are used for $f_{\mathrm{CEO}}$ detection in the $f$-to- 2 -interferometer. The optical spectrum of the 231-fs seed pulses (red), the 85-fs compressed pulses (green), and the optical spectrum analyzer background (gray) are also given. (b) Carrier envelope offset frequency $\left(f_{\text {CEO }}\right)$ detection from the SESAM mode-locked VECSEL. $f_{\text {CEO } 1}$ and $f_{\text {CEO } 2}$ : beat notes at $733 \mathrm{MHz}$ and $1017 \mathrm{MHz}$ in a large span and zoom into $f_{\mathrm{CEO} 1}$ (inset). The decrease of both the signal and noise for higher frequencies is due to the limited bandwidth $\left(f_{3 \mathrm{~dB}} \approx 800 \mathrm{MHz}\right)$ of the photodiode. RBW: resolution bandwidth. (Figures reprinted with permission from Zaugg et al. ${ }^{48}$.

not fully cover an octave, a requirement imposed by the $f$-to- $2 f$ detection scheme to observe the $f_{\text {CEO }}$ beat notes.

Recently, we amplified 231-fs pulses with an average output power of $100 \mathrm{~mW}$ from a 1040-nm mode-locked VECSEL up to several Watts and were able to compress the pulses to $85.4 \mathrm{fs}$ with an average output power of $2.2 \mathrm{~W}^{48}$. A fraction of the available power was launched into a PCF to generate a coherent, octave-spanning SC from $<680 \mathrm{~nm}$ to $>1360 \mathrm{~nm}$ Figure 12a. The dispersive wave centered at $680 \mathrm{~nm}$ and the Raman soliton centered at $1360 \mathrm{~nm}$ were used to generate a CEO beat note in a standard $f$-to- 2 finterferometer, as shown in Figure $12 \mathrm{~b}$. This $f_{\mathrm{CEO}}$ beat note at approximately $733 \mathrm{MHz}$ can be used to stabilize one degree of freedom of the frequency comb generated by the modelocked VECSEL. The CEO beat note shifts when modulating the pump current of the VECSEL, which can be used for a future stabilization of the $\mathrm{CEO}$ frequency. In addition to the $\mathrm{CEO}$ stabilization control via the pump current to the diode pump lasers, the $\mathrm{CEO}$ frequency can also be stabilized by optically pumping the SESAM ${ }^{144}$. Whether this stabilization mechanism is suitable for SESAM mode-locked VECSELs still has to be investigated. For MIXSELs, this result will be even more challenging.

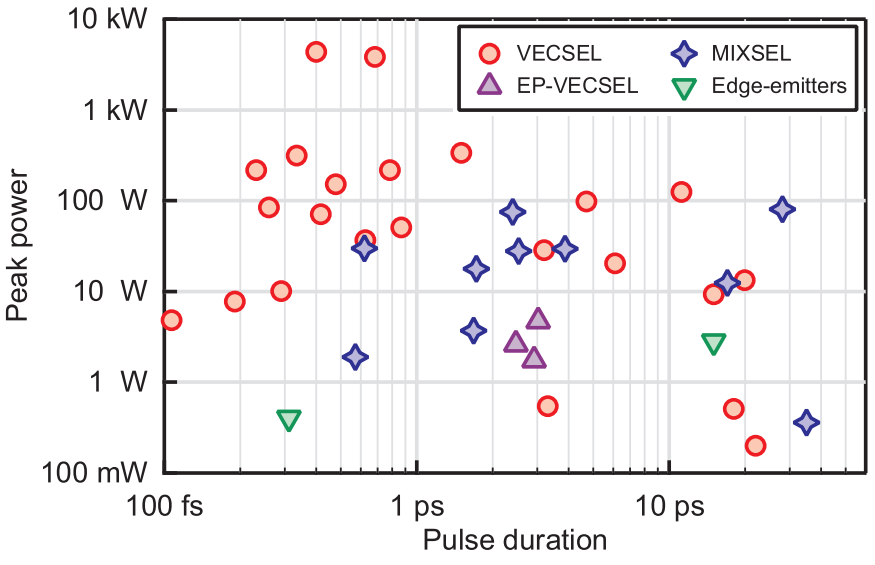

Figure 13 Selected overview of achieved peak powers of fundamentally modelocked optically pumped semiconductor disk lasers versus pulse duration according to Table 1. For comparison, record-reported values of electrically pumped SESAM mode-locked VECSELS and mode-locked edge-emitters are included.

The proof-of-principle CEO-frequency detection from a semiconductor laser is the first step toward a completely stabilized frequency comb from an SDL. The amplification and compression stages used by Zaugg et al. ${ }^{48}$ have to be omitted to provide an advantage over conventional oscillators used for frequency combs. Therefore, we target ultrafast VECSELs, which provide 100-150-fs pulses with average output powers of several hundreds of $\mathrm{mW}$ directly from the oscillator. The rapid progress in the field of SESAM-mode-locked VECSELs $s^{27,28,45}$ and MIXSELs ${ }^{50,51}$ indicates that the desired performance is within reach.

\section{ROADMAP TOWARD SUB-200-FS PULSES AND KW PEAK POWERS}

Many applications, such as frequency comb metrology and biomedical imaging techniques, require ultrashort pulse durations, ideally less than $200 \mathrm{fs}$, in combination with high peak powers in the $\mathrm{kW}$ range. This applies especially for applications where nonlinear effects play a key role, such as coherent SC generation in $\mathrm{PCFs}^{145,146}$. Therefore, significant effort is focused on reducing the pulse duration and increasing the peak power of mode-locked SDLs. The determination of the peak power of a mode-locked SDL requires special care because of the strong tendency for multiple pulsing by over-saturated absorbers, which has been well documented in DPSSLs since as early as $1997^{147}$ and reviewed by Keller in $2007^{148}$. Thus, additional experimental evidence is required for stable fundamental modelocking (e.g., sampling oscilloscope and high-contrast autocorrelators) to confirm that no cw components, very long pulse pedestals or additional satellite pulses are present. A discussion about proving clean modelocking was recently published by Wilcox et $a^{108}$. An overview of SDL peak powers versus pulse duration is given in Figure 13. So far, there have been only three published results with peak powers in the kW range; however, none of these reports have pulse durations in the sub-200 fs regime. In the following section, we intend to discuss the main design and fabrication challenges to achieve ultrashort pulses in combination with high peak powers.

\section{Toward kW peak power}

Output powers of SDLs (average and peak) depend on a delicate balance and optimization of epitaxial design, growth conditions and 
Table $4 \mathrm{Cw}$ average output powers and efficiencies from SDLs.

\begin{tabular}{|c|c|c|c|c|c|c|}
\hline Year & Author & $\lambda_{\mathrm{c}}$ & Opt-opt & Slope & $P_{\mathrm{av}}$ & Single mode \\
\hline 2007 & Kim et al. ${ }^{149}$ & $920 \mathrm{~nm}$ & $50 \%$ & $58 \%$ & $12 \mathrm{~W}$ & No \\
\hline 2008 & Rudin et al. ${ }^{77}$ & $960 \mathrm{~nm}$ & $43 \%$ & $49 \%$ & $20 W$ & Yes \\
\hline 2009 & Demaria et al. ${ }^{151}$ & $970 \mathrm{~nm}$ & $51 \%$ & $56 \%$ & $13 \mathrm{~W}$ & No \\
\hline 2011 & Hader et al. ${ }^{150}$ & $1010 \mathrm{~nm}$ & $37 \%$ & $51 \%$ & $46 \mathrm{~W}$ & No \\
\hline 2012 & Berger et al. ${ }^{113}$ & $1064 \mathrm{~nm}$ & $46 \%$ & $50 \%$ & $60 \mathrm{~W}$ & No \\
\hline 2012 & Heinen et al. ${ }^{78}$ & 1028 nm & $27 \%$ & $40 \%$ & $106 \mathrm{~W}$ & No \\
\hline 2013 & Ranta et al. ${ }^{152}$ & $1180 \mathrm{~nm}$ & $27 \%$ & $33 \%$ & $23 \mathrm{~W}$ & No \\
\hline 2014 & Zhang et al. ${ }^{76}$ & $1013 \mathrm{~nm}$ & $23 \%$ & $33 \%$ & $23 \mathrm{~W}$ & Yes \\
\hline
\end{tabular}

operating conditions, such as heat removal. Several groups have been working on the optimization of $\mathrm{cw}$ average output powers from SDLs ${ }^{149,150}$. Table 4 gives an overview of some of the best reported output power levels, optical-to-optical and slope efficiencies of $\mathrm{cw}$ SDLs with output power levels above $10 \mathrm{~W}$ and slope efficiencies above $30 \%$. No clear relationships between structural design, output power, and efficiency seem to exist.

In addition to optimized epitaxial growth, one of the important design issues to achieve high performance SDLs is the ability to remove heat efficiently from the active region. The quantum defect related to the barrier-pumping and non-radiative recombination processes inherently introduce heat in the active region, which leads to performance degradation and a bandgap shift. Heat removal from the active region can be optimized as follows: using high thermally conductive semiconductors, e.g., favoring the use of GaAs and AlAs above the ternary material AlGaAs, which in most cases, has a lower thermal conductivity; using highly thermal conductive heat-sinks, such as chemical vapor deposited (CVD) diamonds; minimizing the distance between the active region and highly thermally conductive mount(s); and minimizing thermal resistance in the bond between the chip and the mount. In addition, the optical-to-optical efficiency can be improved by reducing the reflectivity of the pump light at the semiconductor interface ${ }^{153}$.

We note a large difference in efficiency when we compare the reported cw output powers and efficiencies from Table 4 with the reported mode-locked output powers and efficiencies in Table 5. A significant part of this decrease can be related to the short carrier lifetimes of a few ns in semiconductors compared to ms or $\mu$ s lifetimes for ion-doped laser crystals. The carrier "leakage" between subsequent pulses due to radiative and non-radiative recombination is significant and reduces the overall efficiency. Therefore, it is important to minimize the impurities and defects in the crystal lattice to minimize deep-level traps and increase the carrier lifetime ${ }^{154}$. Furthermore, the intracavity optical peak intensities are significantly higher than in $\mathrm{cw}$ lasers. This factor inherently means that nonlinear absorption effects, such as two-photon-absorption, are increased and will reduce the efficiency. Therefore, optimizing growth to reduce defects and doping concentrations is crucial. Reducing the field enhancement and, consequently, the intensity in the semiconductor structure is also possible, which needs to be compensated for to obtain sufficient net gain.

The design of the active region plays a key role. Strain compensation in the active region decreases the number of defects in the structure and increases the lifetime of the device. The active layers (QWs or QDs) can be placed exactly in the antinodes of the standing wave pattern (also known as a resonant periodic gain (RPG)), which is normally performed in cw VECSELs to achieve the highest gain. The QW position can also be altered with respect to the antinodes to reduce the field enhancement and increase the gain saturation fluences $^{155}$, which is beneficial for achieving high peak intensities in mode-locked operation. Therefore, a larger number of (or more efficient) active layers are needed to compensate for the overall reduced gain when the field enhancement of the active layers is reduced. Additionally, the QWs can be placed inhomogeneously within the pump-absorbing layer to distribute the excited carriers more equally over the QWs. This result can even be further enforced by introducing carrier barriers in the active region ${ }^{156}$.

\section{Toward sub-200 fs pulses}

The generation of ultrashort pulses in the femtosecond domain depends on a complex combination of parameters in the gain and absorber layers. First, the 1/e recovery time constant of the absorber has to be on the order of a few ps or even sub-ps ${ }^{50,58}$ to enable only a very short net gain window for the interplay between the dynamic gain and absorber saturation (Figure 7). As-grown QDs can exhibit a fast recovery ${ }^{43}$; however, a long annealing time (e.g., during MBE growth after the absorber growth in an MIXSEL) led to very slow recovery times longer than 100 ps with the same absorber ${ }^{49}$. Newly developed fast QW absorbers using AlAs barriers seem to be more resistant to long annealing times. The saturation fluence can be low ${ }^{112}$, and the

Table 5 Selected overview of reported average output powers and efficiencies of mode-locked SDLs.

\begin{tabular}{|c|c|c|c|c|c|c|c|}
\hline Year & Author & $\lambda_{\mathrm{c}}$ & $\tau_{p}$ & $P_{\mathrm{av}}{ }^{\mathrm{a}}$ & $f_{\text {rep }}$ & Pump power & Opt-opt \\
\hline 2002 & Garnache et al. ${ }^{31}$ & 1040 nm & $477 \mathrm{fs}$ & $100 \mathrm{~mW}$ & $1.21 \mathrm{GHz}$ & $1 \mathrm{~W}$ & $10.00 \%$ \\
\hline 2005 & Lindberg et al. ${ }^{30}$ & $1551 \mathrm{~nm}$ & $3.2 \mathrm{ps}$ & $120 \mathrm{~mW}$ & $2.97 \mathrm{GHz}$ & $5 W$ & $2.40 \%$ \\
\hline 2005 & Aschwanden et al. ${ }^{33}$ & $957 \mathrm{~nm}$ & $4.7 \mathrm{ps}$ & $2.1 \mathrm{~W}$ & $4.0 \mathrm{GHz}$ & $18.9 \mathrm{~W}$ & $11.11 \%$ \\
\hline 2008 & Rautiainen et al. ${ }^{66}$ & 1224 nm & $5 \mathrm{ps}$ & $275 \mathrm{~mW}$ & $840 \mathrm{MHz}$ & $8 W$ & $3.44 \%$ \\
\hline 2010 & Wilcox et al. ${ }^{41}$ & 999 nm & $335 \mathrm{fs}$ & $120 \mathrm{~mW}$ & $1.0 \mathrm{GHz}$ & $1.85 \mathrm{~W}$ & $6.49 \%$ \\
\hline 2010 & Rautiainen et al. ${ }^{68}$ & $1312 \mathrm{~nm}$ & $6.4 \mathrm{ps}$ & $100 \mathrm{~mW}$ & $910 \mathrm{MHz}$ & $8.9 \mathrm{~W}$ & $1.12 \%$ \\
\hline 2010 & Rudin et al. ${ }^{26}$ & $959 \mathrm{~nm}$ & $28.1 \mathrm{ps}$ & $6.4 \mathrm{~W}$ & $2.5 \mathrm{GHz}$ & $37 \mathrm{~W}$ & $17.30 \%$ \\
\hline 2011 & Hoffmann et al. ${ }^{43}$ & $961 \mathrm{~nm}$ & 416 fs & $143 \mathrm{~mW}$ & $4.5 \mathrm{GHz}$ & $3.2 \mathrm{~W}$ & $4.47 \%$ \\
\hline 2011 & Hoffmann et al. ${ }^{43}$ & $970 \mathrm{~nm}$ & 784 fs & $1.05 \mathrm{~W}$ & $5.4 \mathrm{GHz}$ & $11.7 \mathrm{~W}$ & $8.97 \%$ \\
\hline 2012 & Wittwer et al. ${ }^{49}$ & $963 \mathrm{~nm}$ & 17 ps & $2.4 \mathrm{~W}$ & $10 \mathrm{GHz}$ & $25.4 \mathrm{~W}$ & $9.45 \%$ \\
\hline 2012 & Scheller et al. ${ }^{45}$ & 1030 nm & $682 \mathrm{fs}$ & $5.1 \mathrm{~W}$ & $1.71 \mathrm{GHz}$ & $37.2 \mathrm{~W}^{\mathrm{b}}$ & $13.71 \%$ \\
\hline 2013 & Wilcox et al. ${ }^{27}$ & $1013 \mathrm{~nm}$ & $400 \mathrm{fs}$ & $3.3 \mathrm{~W}$ & $1.67 \mathrm{GHz}$ & $28.5 \mathrm{~W}$ & $11.58 \%$ \\
\hline 2014 & Mangold et al. ${ }^{51}$ & $963 \mathrm{~nm}$ & $570 \mathrm{fs}$ & $127 \mathrm{~mW}$ & $101.2 \mathrm{GHz}$ & $20.1 \mathrm{~W}$ & $0.63 \%$ \\
\hline 2014 & Mangold et al. ${ }^{51}$ & $964 \mathrm{~nm}$ & $2.4 \mathrm{ps}$ & $1.05 \mathrm{~W}$ & $5.1 \mathrm{GHz}$ & $17.2 \mathrm{~W}$ & $6.10 \%$ \\
\hline 2014 & Zaugg et al. ${ }^{48}$ & 1041 nm & $238 \mathrm{fs}$ & $100 \mathrm{~mW}$ & $1.75 \mathrm{GHz}$ & $11 \mathrm{~W}$ & $0.91 \%$ \\
\hline
\end{tabular}

a Only published results with an average output power above $100 \mathrm{~mW}$ are taken into account.

${ }^{b}$ Only the net pump power is given in this publication. An approximately $30 \%$ reflectivity is assumed based on comparable structures ${ }^{78}$. 

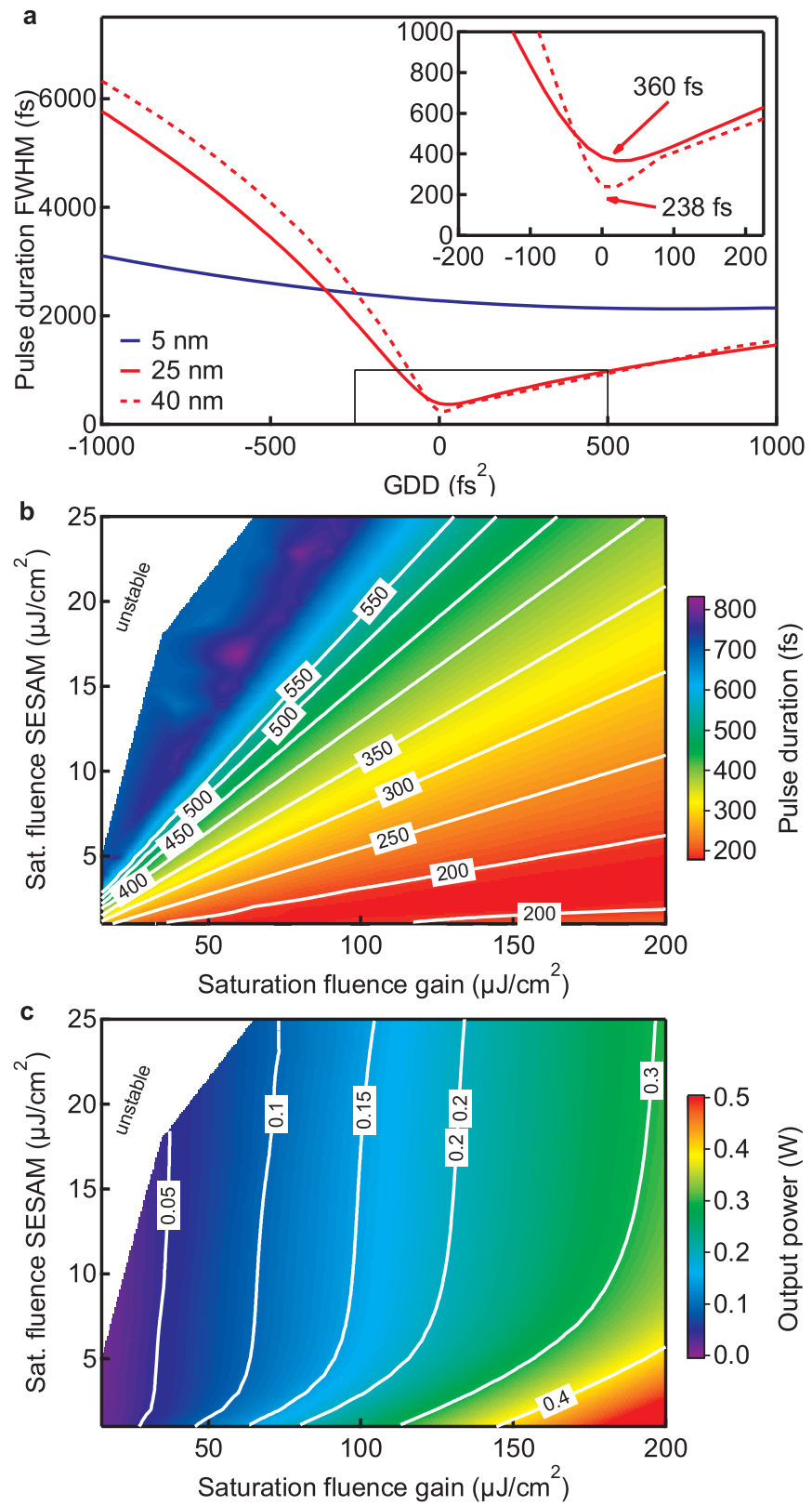

Figure 14 (a) Simulated pulse duration versus total group delay dispersion (GDD) in an SESAM mode-locked VECSEL assuming three different gain bandwidths of 5, 25, and $40 \mathrm{~nm}$. For femtosecond pulses, it is essential to operate at minimized positive GDD in the cavity. (b) Influence of the saturation fluence of the gain and the SESAM on the pulse duration and (c) the average output power. A higher saturation fluence of the gain relaxes the demand for a low saturation fluence for short pulse durations, whereas the output power is mainly influenced by the saturation fluence of the gain. (Figures reprinted with permission from Sieber et al. ${ }^{86}$ )

recovery time can be decreased by reducing the growth temperature ${ }^{50}$. However, the interplay between the absorber and gain saturation is more tricky and more temperature sensitive. Thus, we believe that in the long run, improved QD saturable absorbers may still provide better saturable absorbers in an MIXSEL.

The modelocking mechanism of SDLs relies on a balanced interplay between the saturation effects of the gain and absorber in conjunction with the GDD of the structure ${ }^{99}$. Sieber et al. explored the influence of those effects on the pulse formation process in mode-locked SDLs with an experimentally validated numerical pulse formation simulation based on macroscopically measureable parameters ${ }^{86}$. The simulations revealed that the shortest pulses could be generated with a broadband gain material in combination with a total intracavity GDD close to zero (Figure 14a). Furthermore, the gain saturation fluence should be as high as possible $\left(>200 \mu \mathrm{J} / \mathrm{cm}^{2}\right)$, whereas the absorber saturation fluence must be kept low $\left(<5 \mu \mathrm{J} / \mathrm{cm}^{2}\right)$ to generate sub$200 \mathrm{fs}$ pulses with significant output power (i.e., $>500 \mathrm{~mW}$ average output power) (Figure 14b and 14c). The gain saturation fluences of ultrafast VECSELs have been measured and found to be in the range between 30 and $80 \mu \mathrm{J} / \mathrm{cm}^{2} .{ }^{155}$ Increasing the gain saturation by reducing the field enhancement decreases the small-signal gain, as discussed in the previous subsection, which makes it technologically more challenging to combine sub-200 fs pulses with a high average output power. Recently, the effect of gain saturation has been theoretically studied by Kilen et al. ${ }^{157}$ with a detailed microscopic model. The authors clearly demonstrate the effects of gain saturation and kinetic hole burning in mode-locked lasers. This publication also emphasizes the instabilities in mode-locked operation, such as (unwanted) multipulse formation at high inversion levels.

\section{CONCLUSIONS}

Recent ultrafast SDLs reached a level of maturity that could potentially enable widespread scientific and industrial applications. Pulse durations have been reduced to sub-200 fs, and peak power levels have been reported in the $\mathrm{kW}$-range. The enormous wavelength flexibility and compact design is a large advantage over other types of ultrafast lasers. Furthermore, excellent noise performance, comparable to conventional ion-doped solid-state lasers, allows for exploring the field of ultrastable frequency comb generation. Therefore, an SDL-based ultrastable gigahertz frequency comb could be interesting for several optical measurement techniques, including high-precision optical frequency metrology and spectroscopy, biomedical imaging, optical coherence tomography, and high-speed asynchronous optical sampling.

Current research is focused on increasing the peak power into the $\mathrm{kW}$ range while maintaining clean sub-200-fs pulse durations. In addition to a well-balanced interplay between the gain material, and the saturable absorber and a well-designed dispersion control, research has to focus on the performance of the gain and absorber material. Future improvements in ultrafast SDL designs should increase the efficiency, reduce the thermal side effects and improve the reliability of these devices.

\section{ACKNOWLEDGEMENTS}

The authors acknowledge support of the technology and cleanroom facility FIRST of ETH Zurich for advanced micro- and nanotechnology. This work was financed by the Swiss Confederation Program Nano-Tera.ch, which was scientifically evaluated by the Swiss National Science Foundation (SNSF).

1 Keller U. Recent developments in compact ultrafast lasers. Nature 2003; 424:831 838.

2 Fermann ME, Galvanauskas A, Sucha G. Ultrafast lasers: technology and applications. New York: Taylor \& Francis, 2002

3 Keller U, Weingarten KJ, Kärtner FX, Kopf D, Braun B et al. Semiconductor saturable absorber mirrors (SESAMs) for femtosecond to nanosecond pulse generation in solidstate lasers. IEEE J Sel Topics Quantum Electron 1996; 2: 435-453.

4 Keller U. Ultrafast solid-state laser oscillators: a success story for the last 20 years with no end in sight. App/ Phys B 2010; 100: 15-28.

5 Zehang S, Bebis G, Miller R. On-road vehicle detection: a review. IEEE Trans Pattern Anal Mach Intell 2006; 28: 694-711. 
6 Boehm J. Natural user interface sensors for human body measurement. Int Arch Photogramm Remote Sens Spatial Inf Sci 2012; XXXIX-B3: 531-536.

7 Bartels A, Heinecke D, Diddams SA. 10-GHz self-referenced optical frequency comb. Science 2009; 326: 681.

8 Klenner A, Golling M, Keller U. A gigahertz multimode-diode-pumped Yb:KGW enables a strong frequency comb offset beat signal. Opt Express 2013; $21: 7$.

9 Klenner A, Golling M, Keller U. High peak power gigahertz Yb:CALGO laser. Opt Express 2014; 22: 11884-11891.

10 Williams KA, Thompson MG, White IH. Long-wavelength monolithic mode-locked diode lasers. New J Phys 2004; 6: 179.

11 Avrutin EA, Marsh JH, Portnoi EL. Monolithic and multi-gigahertz mode-locked semiconductor lasers: constructions, experiments, models and applications. IEEE Proc Optoelectron 2000; 147: 251-278.

12 Hohimer JP, Vawter GA. Passive mode locking of monolithic semiconductor ring lasers at $86 \mathrm{GHz}$. Appl Phys Lett 1993; 63: 1598-1600.

13 Bente E, Moskalenko V, Latkowski S, Tahvili S, Augustin L et al. Monolithically integrated InP-based modelocked ring laser systems. Proc. SPIE. 9134, Semiconductor Lasers and Laser Dynamics VI; 2014; 2014. p. 91340C.

14 Smit M, Leiitens X, Bente E, van der Tol J, Ambrosius $\mathrm{H}$ et al. Generic foundry model for InP-based photonics. IET Optoelectron 2011; 5: 187-194.

15 Nagarajan R, Joyner CH, Schneider RP, Bostak JS, Butrie T et al. Large-scale photonic integrated circuits. IEEE J Sel Topics Quantum Electron 2005; 11: 50-65.

16 Lu ZG, Liu JR, Raymond S, Poole PJ, Barrios PJ et al. 312-fs pulse generation from a passive C-band InAs/InP quantum dot mode-locked laser. Opt Express 2008; 16: $10835-10840$.

17 Rosales R, Kalosha VP, Posilović K, Miah MJ, Bimberg D et al. High brightness photonic band crystal semiconductor lasers in the passive mode locking regime. Appl Phys Lett 2014; 105: 161101.

18 Koda R, Oki T, Kono S, Miyajima T, Watanabe $\mathrm{H}$ et al. $300 \mathrm{~W}$ peak power picosecond optical pulse generation by blue-violet GalnN mode-locked laser diode and semiconductor optical amplifier. Appl Phys Express 2012; 5: 022702.

19 Balzer JC, Schlauch T, Klehr A, Erbert G, Tränkle G et al. High peak power pulses from dispersion optimised modelocked semiconductor laser. Electron Lett 2013; 49: 838-839.

20 Derickson DJ, Morton PA, Bowers JE, Thornton RL. Comparison of timing jitter in external and monolithic cavity mode-locked semiconductor lasers. Appl Phys Lett 1991; 59: 3372-3374.

21 Kuznetsov M, Hakimi F, Sprague R, Mooradian A. High-power (>0.5-W CW) diodepumped vertical-external-cavity surface-emitting semiconductor lasers with circular TEM 0 beams. IEEE Photon Technol Lett 1997; 9: 1063-1065.

22 Saraceno CJ, Emaury F, Schriber C, Diebold A, Hoffmann M et al. Toward millijoulelevel high-power ultrafast thin-disk oscillators. IEEE J Sel Topics Quantum Electron 2015; 21: 1100318.

23 Maas DJHC, Bellancourt A-R, Rudin B, Golling M, Unold HJ et al. Vertical integration of ultrafast semiconductor lasers. Appl Phys B 2007; 88: 493-497.

24 Bellancourt A-R, Maas DJHC, Rudin B, Golling M, Südmeyer T et al. Modelocked integrated external-cavity surface emitting laser (MIXSEL). IET Optoelectron 2009; 3: 61-72.

25 Hoogland S, Dhanjal S, Tropper AC, Roberts SJ, Häring R et al. Passively modelocked diode-pumped surface-emitting semiconductor laser. IEEE Photon Technol Lett 2000; 12: 1135-1138.

26 Rudin B, Wittwer VJ, Maas DJHC, Hoffmann M, Sieber OD et al. High-power MIXSEL: an integrated ultrafast semiconductor laser with $6.4 \mathrm{~W}$ average power. Opt Express 2010; 18: 27582-27588.

27 Wilcox KG, Tropper AC, Beere HE, Ritchie DA, Kunert B et al. 4.35 kW peak power femtosecond pulse mode-locked VECSEL for supercontinuum generation. Opt Express 2013; 21: 1599-1605.

28 Klopp P, Griebner U, Zorn M, Weyers M. Pulse repetition rate up to $92 \mathrm{GHz}$ or pulse duration shorter than $110 \mathrm{fs}$ from a mode-locked semiconductor disk laser. Appl Phys Lett 2011; 98: 071103-071103.

29 Quarterman AH, Wilcox KG, Apostolopoulos V, Mihoubi Z, Elsmere SP et al. A passively mode-locked external-cavity semiconductor laser emitting 60-fs pulses. Nature Photon 2009; 3: 729-731.

30 Lindberg H, Sadeghi M, Westlund M, Wang S, Larsson A et al. Mode locking a $1550 \mathrm{~nm}$ semiconductor disk laser by using a GalnNAs saturable absorber. Opt Lett 2005; 30: 2793-2795

31 Garnache A, Hoogland S, Tropper AC, Sagnes I, Saint-Girons G et al. Sub-500-fs soliton pulse in a passively mode-locked broadband surface-emitting laser with 100-mW average power. Appl Phys Lett 2002; 80: 3892-3894.

32 Haring R, Paschotta R, Aschwanden A, Gini E, Morier-Genoud F et al. High-power passively mode-locked semiconductor lasers. IEEE J Quantum Electron 2002; 38: 1268-1275.

33 Aschwanden A, Lorenser D, Unold HJ, Paschotta R, Gini E et al. 2.1-W picosecond passively mode-locked external-cavity semiconductor laser. Opt Lett 2005; 30: 272274.

34 Aschwanden A, Lorenser D, Unold HJ, Paschotta R, Gini E et al. 10-GHz passively mode-locked surface emitting semiconductor laser with 1.4-W average output power. App/ Phys Lett 2005; 86: 131102

35 Lorenser D, Maas DJHC, Unold HJ, Bellancourt A-R, Rudin B et al. 50-GHz passively mode-locked surface-emitting semiconductor laser with $100 \mathrm{~mW}$ average output power. IEEE J Quantum Electron 2006; 42: 838-847.

36 Klopp P, Saas F, Zorn M, Weyers M, Griebner U. 290-fs pulses from a semiconductor disk laser. Opt Express 2008; 16: 5770-5775.
37 Hoffmann M, Barbarin Y, Maas DJHC, Golling M, Krestnikov IL et al. Modelocked quantum dot vertical external cavity surface emitting laser. Appl Phys B 2008; 93: 733-736.

38 Wilcox KG, Mihoubi Z, Daniell GJ, Elsmere S, Quarterman A et al. Ultrafast optical Stark mode-locked semiconductor laser. Opt Lett 2008; 33: 2797-2799.

39 Wilcox KG, Butkus M, Farrer I, Ritchie DA, Tropper A et al. Subpicosecond quantum dot saturable absorber mode-locked semiconductor disk laser. Appl Phys Lett 2009; 94: 3.

40 Klopp P, Griebner U, Zorn M, Klehr A, Liero A et al. Mode-locked InGaAs-AIGaAs disk laser generating sub-200-fs pulses, pulse picking and amplification by a tapered diode amplifier. Opt Express 2009; 17: 10820-10834.

41 Wilcox KG, Quarterman AH, Beere H, Ritchie DA, Tropper AC. High peak power femtosecond pulse passively mode-locked vertical-external-cavity surface-emitting laser. IEEE Photon Technol Lett 2010; 22: 1021-1023.

42 Aviles-Espinosa R, Filippidis G, Hamilton C, Malcolm G, Weingarten KJ et al. Compact ultrafast semiconductor disk laser: targeting GFP based nonlinear applications in living organisms. Biomed Opt Express 2011; 2: 739-747.

43 Hoffmann M, Sieber OD, Wittwer VJ, Krestnikov IL, Livshits DA et al. Femtosecond high-power quantum dot vertical external cavity surface emitting laser. Opt Express 2011; 19: 8108-8116.

44 Sieber OD, Wittwer VJ, Mangold M, Hoffmann M, Golling M et al. Femtosecond VECSEL with tunable multi-gigahertz repetition rate. Opt Express 2011; 19: 23538-23543.

45 Scheller M, Wang TL, Kunert B, Stolz W, Koch SW et al. Passively modelocked VECSEL emitting 682 fs pulses with $5.1 \mathrm{~W}$ of average output power. Electron Lett 2012; 48: 588-589.

46 Zaugg CA, Hoffmann M, Pallmann WP, Wittwer VJ, Sieber OD et al. Low repetition rate SESAM modelocked VECSEL using an extendable active multipass-cavity approach. Opt Express 2012; 20: 27915-27921.

47 Zaugg CA, Klenner A, Sieber OD, Golling M, Tilma BW et al. Sub-100 MHz passively modelocked VECSEL. CLEO: 2013; 2013; San Jose, CA; 2013. p. CW1G.6.

48 Zaugg CA, Klenner A, Mangold M, Mayer AS, Link SM et al. Gigahertz selfreferenceable frequency comb from a semiconductor disk laser. Opt Express 2014; 22: 16445-16455

49 Wittwer VJ, Mangold M, Hoffmann M, Sieber OD, Golling M et al. High-power integrated ultrafast semiconductor disk laser: multi-Watt $10 \mathrm{GHz}$ pulse generation. Electron Lett 2012; 48: 1144-1145.

50 Mangold M, Wittwer VJ, Zaugg CA, Link SM, Golling M et al. Femtosecond pulses from a modelocked integrated external-cavity surface emitting laser (MIXSEL). Opt Express 2013; 21: 24904-24911.

51 Mangold M, Zaugg CA, Link SM, Golling M, Tilma BW et al. Pulse repetition rate scaling from 5 to $100 \mathrm{GHz}$ with a high-power semiconductor disk laser. Opt Express 2014; 22: 6099-6107.

52 Zaugg CA, Gronenborn S, Moench H, Mangold M, Miller M et al. Absorber and gain chip optimization to improve performance from a passively modelocked electrically pumped vertical external cavity surface emitting laser. App/ Phys Lett 2014; 104: 121115.

53 Park SH, Kim J, Jeon H, Sakong T, Lee SN etal. Room-temperature GaN vertical-cavity surface-emitting laser operation in an extended cavity scheme. Appl Phys Lett 2003, 83: 2121-2123.

54 Rahim M, Arnold M, Felder F, Behfar K, Zogg H. Midinfrared lead-chalcogenide vertical external cavity surface emitting laser with $5 \mu \mathrm{m}$ wavelength. Appl Phys Lett 2007; 91: 151102

55 Rahim M, Felder F, Fill M, Zogg H. Optically pumped $5 \mu \mathrm{m}$ IV-VI VECSEL with Al-heat spreader. Opt Lett 2008; 33: 3010-3012.

56 Rahim M, Khiar A, Felder F, Fill M, Zogg H et al. 5- $\mu m$ vertical external-cavity surfaceemitting laser (VECSEL) for spectroscopic applications. Appl Phys B 2010; 100: 261-264.

57 Tropper AC, Foreman HD, Garnache A, Wilcox KG, Hoogland SH. Vertical-externalcavity semiconductor lasers. J Phys D: Appl Phys 2004; 37: R75-R85.

58 Keller U, Tropper AC. Passively modelocked surface-emitting semiconductor lasers. Phys Rep 2006; 429: 67-120.

59 Schulz N, Hopkins JM, Rattunde M, Burns D, Wagner J. High-brightness longwavelength semiconductor disk lasers. Laser Photon Rev 2008; 2: 160-181.

60 Calvez S, Hastie JE, Guina M, Okhotnikov OG, Dawson MD. Semiconductor disk lasers for the generation of visible and ultraviolet radiation. Laser Photon Rev 2009; 3: 407-434.

61 Kaneda Y, Yarborough JM, Li L, Peyghambarian N, Fan L et al. Continuous-wave all-solid-state $244 \mathrm{~nm}$ deep-ultraviolet laser source by fourth-harmonic generation of an optically pumped semiconductor laser using CsLiB6O10 in an external resonator. Opt Lett 2008; 33: 1705-1707.

62 Bek R, Kersteen G, Kahle H, Schwarzbäck T, Jetter M et al. All quantum dot modelocked semiconductor disk laser emitting at $655 \mathrm{~nm}$. Appl Phys Lett 2014; 105: 082107.

63 Bek R, Kahle H, Schwarzback T, Jetter M, Michler P. Mode-locked red-emitting semiconductor disk laser with sub-250 fs pulses. Appl Phys Lett 2013; 103: 242101

64 Ranta S, Härkönen A, Leinonen T, Orsila L, Lyytikäinen J et al. Mode-locked VECSEL emitting 5 ps pulses at $675 \mathrm{~nm}$. Opt Lett 2013; 38: 2289-2291.

65 Wilcox KG, Mihoubi Z, Elsmere S, Quarterman A, Foreman HD et al. Passively modelocked $832 \mathrm{~nm}$ vertical-external-cavity surface-emitting semiconductor laser producing 15.3 ps pulses at $1.9 \mathrm{GHz}$ repetition rate. Electron Lett 2008; 44: $1469-1470$. 
66 Rautiainen J, Korpijärvi V-M, Puustinen J, Guina M, Okhotnikov OG. Passively modelocked GalnNAs disk laser operating at $1220 \mathrm{~nm}$. Opt Express 2008; 16: 15964 15969.

67 Rutz A, Liverini V, Maas DJHC, Rudin B, Bellancourt A-R et al. Passively modelocked GalnNAs VECSEL at centre wavelength around 1.3. Electron Lett 2006; 42: 926.

68 Rautiainen J, Lyytikainen J, Toikkanen L, Nikkinen J, Sirbu A et al. 1.3- $\mu$ m Modelocked disk laser with wafer fused gain and SESAM structures. IEEE Photon Technol Lett 2010; 22: 748-750.

69 Hoogland S, Paldus B, Garnache A, Weingarten KJ, Grange R et al. Picosecond pulse generation with a $1.5 \mu \mathrm{m}$ passively modelocked surface emitting semiconductor laser. Electron Lett 2003; 39: 846.

70 Zhao Z, Bouchoule S, Song J, Galopin E, Harmand J-C et al. Subpicosecond pulse generation from a $1.56 \mu$ m mode-locked VECSEL. Opt Lett 2011; 36: 4377-4379.

71 Härkönen A, Paajaste J, Suomalainen S, Alanko J-P, Grebing C et al. Picosecond passively mode-locked GaSb-based semiconductor disk laser operating at $2 \mu \mathrm{m}$. Opt Lett 2010; 35: 4090-4092.

72 Härkönen A, Grebing C, Paajaste J, Koskinen R, Alanko J-P et al. Modelocked GaSb disk laser producing 384 fs pulses at $2 \mu \mathrm{m}$ wavelength. Electron Lett 2011; 47: 454-456.

73 Härkönen A, Rautiainen J, Orsila L, Guina M, Rößner K et al. 2- $\mu$ m Mode-locked semiconductor disk laser synchronously pumped using an amplified diode laser. IEEE Photon Technol Lett 2008; 20: 1332-1334.

74 Kemp AJ, Valentine GJ, Hopkins JM, Hastie JE, Smith SA et al. Therma management in vertical-external-cavity surface-emitting lasers: finite-element analysis of a heatspreader approach. IEEE J Quantum Electon 2005; 41: 148-155.

75 Giesen A, Hügel H, Voss A, Wittig K, Brauch U et al. Scalable concept for diodepumped high-power solid-state lasers. Appl Phys B 1994; 58: 365-372.

76 Zhang F, Heinen B, Wichmann M, M̂ller C, Kunert B et al. A 23-watt single-frequency vertical-external-cavity surface-emitting laser. Opt Express 2014; 22: 12817-12822.

77 Rudin B, Rutz A, Hoffmann M, Maas DJHC, Bellancourt A-R et al. Highly efficient optically pumped vertical emitting semiconductor laser with more than 20-W average output power in a fundamental transverse mode. Opt Lett 2008; 33: 2719-2721.

78 Heinen B, Wang TL, Sparenberg M, Weber A, Kunert B et al. 106 W continuous-wave output power from vertical-external-cavity surface-emitting laser. Electron Lett2012; 48: 516-517

79 Mclnerney JG, Mooradian A, Lewis A, Shchegrov AV, Strzelecka EM et al. High-power surface emitting semiconductor laser with extended vertical compound cavity. Electron Lett 2003; 39: 523-525.

80 Zhao P, Xu B, van Leeuwen R, Chen T, Watkins L et al. Compact 4.7 W, 18.3\% wall-plug efficiency green laser based on an electrically pumped VECSEL using intracavity frequency doubling. Opt Lett 2014; 39: 4766-4768.

81 Kreuter P, Witzigmann B, Maas DJHC, Barbarin Y, Südmeyer T et al. On the design of electrically-pumped vertical-external-cavity surface-emitting lasers. Appl Phys $B$ 2008; 91: 257-264.

82 Barbarin Y, Hoffmann M, Pallmann WP, Dahhan I, Kreuter P et al. Electrically pumped vertical external cavity surface emitting lasers suitable for passive modelocking. IEEE J Sel Topics Quantum Electron 2011; 17: 1779-1786.

83 Keller U, Miller DAB, Boyd GD, Chiu TH, Ferguson JF et al. Solid-state low-loss intracavity saturable absorber for Nd:YLF lasers: an antiresonant semiconductor Fabry-Perot saturable absorber. Opt Lett 1992; 17: 505-507.

84 Spühler GJ, Weingarten KJ, Grange R, Krainer L, Haiml M et al. Semiconductor saturable absorber mirror structures with low saturation fluence. Appl Phys B 2005; 81: 27-32.

85 Maas DJHC, Rudin B, Bellancourt A-R, Iwaniuk D, Marchese SV et al. High precision optical characterization of semiconductor saturable absorber mirrors. Opt Express 2008; 16: 7571-7579.

86 Sieber OD, Hoffmann M, Wittwer VJ, Mangold M, Golling M et al. Experimentally verified pulse formation model for high-power femtosecond VECSELs. Appl Phys $B$ 2013; 113: 133-145

87 Grange R, Haiml M, Paschotta R, Spuhler GJ, Krainer L et al. New regime of inverse saturable absorption for self-stabilizing passively mode-locked lasers. Appl Phys $B$ 2005; 80: 151-158.

88 Siegner U, Haiml M, Morier-Genoud F, Lutz RC, Specht $\mathrm{P}$ et al. Femotsecond nonlinear optics of low-temperature grown semiconductors. Phys B 1999; 273274: 733-736

89 Haiml M, Siegner U, Morier-Genoud F, Keller U, Luysberg M et al. Optical nonlinearity in low-temperature-grown GaAs: microscopic limitations and optimization strategies. Appl Phys Lett 1999; 74: 3134-3136.

90 Haiml M, Siegner U, Morier-Genoud F, Keller U, Luysberg M et al. Femtosecond response times and high optical nonlinearity in Beryllium doped low-temperature grown GaAs. Appl Phys Lett 1999; 74: 1269-1271.

91 Liverini V, Schön S, Grange R, Haiml M, Zeller SC et al. A low-loss GalnNAs SESAM mode-locking a 1.3- $\mu \mathrm{m}$ solid-state laser. Appl Phys Lett 2004; 84: 4002-4004.

92 Lederer MJ, Luther-Davies B, Tan HH, Jagadish C, Haiml M et al. Nonlinear optical absorption and temporal response of Arsenic- and Oxygen-implanted GaAs. Appl Phys Lett 1999; 74: 1993-1995.

93 Tan HH, Jagadish C, Lederer MJ, Luther-Davies B, Zou J et al. Role of implantationinduced defects on the response time of semiconductor saturable absorbers. App Phys Lett 1999; 75: 1437-1439.

94 Ostinelli O, Bächtold W, Haiml H, Grange R, Keller U et al. Carrier lifetime reduction in $1.5 \mu \mathrm{m} \mathrm{AIGaAsSb}$ saturable absorbers with air and AlAsSb barriers. Appl Phys Let 2006; 89: 071114
95 Mysyrowicz A, Hulin D, Antonetti A, Migus A. "Dresses excitons" in a multiplequantum-well structure: evidence for an optical stark effect with femtosecond response time. Phys Rev Lett 1986; 56: 2748-2751.

96 Tsuda S, Knox WH, Cundiff ST, Jan WY, Cunningham JE. Mode-locking ultrafast solid state lasers with saturable Bragg reflectors. IEEE J Sel Topics Quantum Electron 1996; 2 : 454-464.

97 Quarterman AH, Carswell S, Daniell GJ, Mihoubi Z, Wilcox KG et al. Numerical simulation of optical Stark effect saturable absorbers in mode-locked femtosecond VECSELs using a modified two-level atom model. Opt Express 2011; 19: 2678326795.

98 Saraceno CJ, Heckl OH, Baer CRE, Golling M, Südmeyer T et al. SESAMs for highpower femtosecond modelocking: power scaling of an $\mathrm{Yb}: \mathrm{LuScO}_{3}$ thin disk laser to $23 \mathrm{~W}$ and 235 fs. Opt Express 2011; 19: 20288-20300.

99 Paschotta R, Häring R, Keller U, Garnache A, Hoogland S et al. Soliton-like pulseshaping mechanism in passively mode-locked surface-emitting semiconductor lasers. Appl Phys B 2002; 75: 445-451.

100 Maas DJHC, Bellancourt AR, Hoffmann M, Rudin B, Barbarin Y et al. Growth parameter optimization for fast quantum dot SESAMs. Opt Express 2008; 16 : $18646-18656$.

101 Zaugg CA, Sun Z, Wittwer VJ, Popa D, Milana S et al. Ultrafast and widely tuneable vertical-external-cavity surface-emitting laser, mode-locked by a graphene-integrated distributed Bragg reflector. Opt Express 2013; 21: 31548-31559.

102 Husaini S, Bedford RG. Graphene saturable absorber for high power semiconductor disk laser mode-locking. Appl Phys Lett 2014; 104: 161107.

103 Kornaszewski L, Maker G, Malcolm GPA, Butkus M, Rafailov EU et al. SESAM-free mode-locked semiconductor disk laser. Laser Photon Rev 2012; 6: L20-L23.

104 Albrecht AR, Wang Y, Ghasemkhani M, Seletskiy DV, Cederberg JG et al. Exploring ultrafast negative Kerr effect for mode-locking vertical external-cavity surfaceemitting lasers. Opt Express 2013; 21: 28801-28808.

105 Gaafar M, Möller C, Wichmann M, Heinen B, Kunert B et al. Harmonic self-modelocking of optically pumped semiconductor disc laser. Electron Lett 2014; 50: 542543.

106 Moloney JV, Kilen I, Bäumner A, Scheller M, Koch SW. Nonequilibrium and thermal effects in mode-locked VECSELs. Opt Express 2014; 22: 6422-6427.

107 Spence DE, Evans JM, Sleat WE, Sibbett W. Regenerately initiated self-modelocked Ti:Sapphire laser. Optics Lett 1991; 16: 1762-1764.

108 Wilcox KG, Tropper AC. Comment on SESAM-free mode-locked semiconductor disk laser. Laser Photon Rev 2013; 7: 422-423.

109 Gaafar M, Richter P, Keskin H, Möller C, Wichmann M et al. Self-mode-locking semiconductor disk laser. Opt Express 2014; 22: 28390-28399.

110 Lorenser D, Unold HJ, Maas DJHC, Aschwanden A, Grange R et al. Towards waferscale integration of high repetition rate passively mode-locked surface-emitting semiconductor lasers. Appl Phys B 2004; 79: 927-932.

111 Bellancourt A-R, Barbarin Y, Maas DJHC, Shafiei M, Hoffmann M et al. Low saturation fluence antiresonant quantum dot SESAMs for MIXSEL integration. Opt Express 2009; 17: 9704-9711.

112 Wittwer VJ, Sieber OD, Mangold M, Hoffmann M, Saraceno CJ et al. First MIXSEL with a quantum well saturable absorber: shorter pulse durations and higher repetition rates. CLEO US 2012; 2012; San Jose; 2012.

113 Berger JD, Anthon DW, Caprara A, Chilla JL, Govorkov SV et al. 20 Watt CW TEMoo intracavity doubled optically pumped semiconductor laser at $532 \mathrm{~nm}$. Proc. SPIE 8242, Vertical External Cavity Surface Emitting Lasers (VECSELs) II; 2012; 2012. p. 824206.

114 Hönninger C, Paschotta R, Morier-Genoud F, Moser M, Keller U. Q-switching stability limits of continuous-wave passive mode locking. J Opt Soc Am B 1999; 16: 46-56.

115 Saarinen EJ, Harkonen A, Herda R, Suomalainen S, Orsila L et al. Harmonically mode-locked VECSELs for multi-GHz pulse train generation. Opt Express 2007, 15: 955-964.

116 Hastie JE, Hopkins JM, Jeon CW, Calvez S, Burns D et al. Microchip vertical external cavity surface emitting lasers. Electron Lett 2003; 39: 1324-1326.

117 Laurand N, Lee CL, Gu E, Hastie JE, Calvez S et al. Microlensed microchip VECSEL. Opt Express 2007; 15: 9341-9346.

118 Wilcox KG, Quarterman AH, Beere HE, Ritchie DA, Tropper AC. Repetitionfrequency-tunable mode-locked surface emitting semiconductor laser between 2.78 and $7.87 \mathrm{GHz}$. Opt Express 2011; 19: 23453-23459.

119 Wilcox KG, Quarterman AH, Beere HE, Ritchie DA, Tropper AC. Variable repetition frequency femtosecond-pulse surface emitting semiconductor laser. Appl Phys Lett 2011; 99: 131107.

120 Schlatter A, Rudin B, Zeller SC, Paschotta R, Spühler GJ et al. Nearly quantum-noiselimited timing jitter from miniature Er:Yb:glass lasers. Opt Lett 2005; 30: 15361538

121 Schilt S, Bucalovic N, Dolgovskiy V, Schori C, Stumpf MC et al. Fully stabilized optical frequency comb with sub-radian CEO phase noise from a SESAMmodelocked 1.5- $\mu \mathrm{m}$ solid-state laser. Opt Express 2011; 19: 24171-24181.

122 Hillerkuss D, Schmogrow R, Schellinger T, Jordan M, Winter M et al. 26 Tbit s $^{-1}$ line-rate super-channel transmission utilizing all-optical fast Fourier transform processing. Nat Photon 2011; 5: 364-371.

123 Wilcox KG, Foreman HD, Roberts JS, Tropper AC. Timing jitter of $897 \mathrm{MHz}$ optical pulse train from actively stabilised passively modelocked surface-emitting semiconductor laser. Electron Lett 2006; 42: 159-160.

124 Quarterman AH, Wilcox KG, Elsmere SP, Mihoubi Z, Tropper AC. Active stabilisation and timing jitter characterisation of sub-500 fs pulse passively modelocked VECSEL. Electron Lett 2008; 44: 1135-1137. 
125 Wittwer VJ, Zaugg CA, Pallmann WP, Oehler AEH, Rudin B et al. Timing jitter characterization of a free-running SESAM mode-locked VECSEL. IEEE Photon $\mathrm{J}$ 2011; 3: 658-664

126 Wittwer VJ, van der Linden R, Tilma BW, Resan B, Weingarten KJ et al. Sub-60-fs timing jitter of a SESAM modelocked VECSEL. IEEE Photon J 2012; 5: 1400107.

127 Mangold M, Link SM, Klenner A, Zaugg CA, Golling M et al. Amplitude noise and timing jitter characterization of a high-power mode-locked integrated external-cavity surface emitting laser. IEEE Photon J 2014; 6: 1500309.

128 Klenner A, Schilt S, Şdmeyer T, Keller U. Gigahertz frequency comb from a diodepumped solid-state laser. Opt Express 2014; 22: 31008-31019.

129 Paschotta R, Schlatter A, Zeller SC, Telle HR, Keller U. Optical phase noise and carrier-envelope offset noise of mode-locked lasers. Appl Phys B 2006; 82: 265-273.

130 Paschotta R, Telle HR, Keller U. Noise of Solid-State Lasers. In: Sennaroglu A (ed). Solid-state lasers and applications. Boca Raton: CRC Press Taylor and Francis Group 2007, pp 473-510.

131 Heck MJR, Salumbides EJ, Renault A, Bente EAJM, Oei Y-S et al. Analysis of hybrid mode-locking of two-section quantum dot lasers operating at $1.5 \mu \mathrm{m}$. Opt Express 2009; 17: 18063-18075.

132 Chang-Yi L, Grillot F, Yan L, Raghunathan R, Lester LF. Microwave characterization and stabilization of timing jitter in a quantum-dot passively mode-locked laser via external optical feedback. IEEE J Sel Topics Quantum Electron 2011; 17: 1311-1317.

133 Drzewietzki L, Breuer S, Elsäfler W. Timing jitter reduction of passively mode-locked semiconductor lasers by self- and external-injection: numerical description and experiments. Opt Express 2013; 21: 16142-16161.

134 Telle HR, Steinmeyer G, Dunlop AE, Stenger J, Sutter DH et al. Carrier-envelope offset phase control: a novel concept for absolute optical frequency measurement and ultrashort pulse generation. Appl Phys B 1999; 69: 327-332.

135 Rodwell MJW, Bloom DM, Weingarten KJ. Subpicosecond laser timing stabilization. IEEE J Quantum Electron 1989; 25: 817-827.

136 Keller U, Li KD, Rodwell MJW, Bloom DM. Noise characterization of femtosecond fiber Raman soliton lasers. IEEE J Quantum Electron 1989; 25: 280-288.

137 Jones DJ, Diddams SA, Ranka JK, Stentz A, Windeler RS et al. Carrier-envelope phase control of femtosecond mode-locked lasers and direct optical frequency synthesis. Science 2000; 288: 635-639.

138 Washburn BR, Diddams SA, Newbury NR, Nicholson JW, Yan MF et al. Phase-locked, erbium-fiber-laser-based frequency comb in the near infrared. Opt Lett 2004; 29: 250-252.

139 Klenner A, Emaury F, Schriber C, Diebold A, Saraceno CJ et al. Phase-stabilization of the carrier-envelope-offset frequency of a SESAM modelocked thin disk laser. Opt Express 2013; 21: 24770-24780.

140 Russell P. Photonic crystal fibers. Science 2003; 299: 358-362.

141 Quarterman AH, Hooper LE, Mosley PJ, Wilcox KG. Gigahertz pulse source by compression of mode-locked VECSEL pulses coherently broadened in the normal dispersion regime. Opt Express 2014; 22: 12096-12101.
142 Chamorovskiy A, Kerttula J, Rautiainen J, Okhotnikov OG. Supercontinuum generation with amplified $1.57 \mu \mathrm{m}$ picosecond semiconductor disk laser. Electron Lett 2012; 48: 1010-1012.

143 Morioka T, Kawanishi S, Mori K, Saruwatari M. Nearly penalty-free, $<4$ ps supercontinuum Gbit/s pulse generation over 1535-1560 nm. Electron Lett 1994; 30: 790-791.

144 Hoffmann M, Schilt S, Südmeyer T. CEO stabilization of a femtosecond laser using a SESAM as fast opto-optical modulator. Opt Express 2013; 21: 30054-30064.

145 Dudley JM, Genty G, Coen S. Supercontinuum generation in photonic crystal fiber. Rev Mod Phys 2006; 78: 1135-1184.

146 Dudley JM, Coen S. Coherence properties of supercontinuum spectra generated in photonic crystal and tapered optical fibers. Opt Lett 2002; 27: 1180-1182.

147 Kopf D, Prasad A, Zhang G, Moser M, Keller U. Broadly tunable femtosecond Cr: LiSAF laser. Optics Lett 1997; 22: 621-623.

148 Keller U. Ultrafast solid-state lasers. In: Herziger G, Weber H, Proprawe R (eds). Landolt-Börnstein. Laser physics and applications. Subvolume B: laser systems. Part I., vol. 1, Group VIII. Springer Verlag: Heidelberg, 2007, pp 33-167.

149 Kim KS, Yoo J, Kim G, Lee S, Cho S et al. 920-nm vertical-external-cavity surfaceemitting lasers with a slope efficiency of $58 \%$ at room temperature. IEEE Photon Technol Lett 2007; 19: 1655-1657.

150 Hader J, Wang TL, Yarborough JM, Dineen CA, Kaneda Y et al. VECSEL optimization using microscopic many-body physics. IEEE J Sel Topics Quantum Electron 2011; 17: $1753-1762$.

151 Demaria F, Lorch S, Menzel S, Riedl MC, Rinaldi F et al. Design of highly efficient high-power optically pumped semiconductor disk lasers. IEEE J Sel Topics Quantum Electron 2009; 15: 973-977.

152 Ranta S, Tavast M, Leinonen T, Lieu NV, Fetzer G et al. 1180 nm VECSEL with output power beyond 20 W. Electron Lett 2013; 49: 59-60.

153 Kühn E, Thränhardt A, Bückers C, Koch SW, Hader J et al. Numerical study of the influence of an antireflection coating on the operating properties of vertical-externalcavity surface-emitting lasers. J Appl Phys 2009; 106: 063105.

154 Lin GR, Liu TA, Pan CL. Correlation between defect concentration and carrier lifetime of GaAs grown by molecular beam epitaxy at different temperatures. Jpn J Appl Phys 2001; 40: 6239-6242.

155 Mangold M, Wittwer VJ, Sieber OD, Hoffmann M, Krestnikov IL et al. VECSEL gain characterization. Opt Express 2012; 20: 4136-4148.

156 Geske J, Gan KG, Okuno YL, Piprek J, Bowers JE. Vertical-cavity surface-emitting laser active regions for enhanced performance with optical pumping. IEEE J Quantum Electron 2004; 40: 1155-1162.

157 Kilen I, Hader J, Moloney JV, Koch SW. Ultrafast nonequilibrium carrier dynamics in semiconductor laser mode locking. Optica 2014; 1: 192-197.

(c) (i) This license allows readers to copy, distribute and transmit the Contribution cc) as long as it attributed back to the author. Readers are permitted to alter, transform or build upon the Contribution, and use the article for commercial purposes. Please read the full license for further details at - http://creativecommons.org/licenses/by/4.0/ 